\title{
Recruitment of RNA polymerase III to its target promoters
}

\author{
Laura Schramm and Nouria Hernandez ${ }^{1}$ \\ Howard Hughes Medical Institute, Cold Spring Harbor Laboratory, Cold Spring Harbor, New York 11724, USA
}

A key step in retrieving the information stored in the complex genomes of eukaryotes involves the identification of transcription units and, more specifically, the recognition of promoter sequences by RNA polymerase. In eukaryotes, the task of recognizing nuclear gene promoters and then transcribing the genes is divided among three highly related enzymes, RNA polymerases I, II, and III. Each of these RNA polymerases is dedicated to the transcription of specific sets of genes, and each depends on accessory factors, the so-called transcription factors, to recognize its cognate promoter sequences.

RNA polymerase I is unique among the nuclear RNA polymerases in transcribing only one set of genes, the large, tandemly repeated, ribosomal RNA genes, and thus in having to recognize a single promoter structure. RNA polymerase II transcribes the protein-coding genes (mRNA genes) as well as some small nuclear RNA (snRNA) genes. The RNA polymerase II promoters can be divided into a core region, defined as the minimal region capable of directing transcription in vitro, and a regulatory region. The regulatory regions are highly varied in structure, reflecting the highly varied synthesis patterns of cellular proteins and the need for exquisite and complex regulation of these patterns. The core promoters themselves come in different types that, in mRNA-encoding genes, can contain a TATA box, an initiator, a downstream promoter element, or various combinations thereof. The assembly of a functional RNA polymerase II transcription complex on a promoter consisting of just a TATA box has been extensively studied. All the factors involved in the process have been identified, and much is known about how these factors interact with DNA and with each other to recruit, eventually, RNA polymerase II (for reviews, see Orphanides et al. 1996; Woychik and Hampsey 2002). How RNA polymerase II transcription complexes assemble on TATA-less promoters is, however, not as well understood.

RNA polymerase III is dedicated to the transcription of an eclectic collection of genes whose main common features are that they encode structural or catalytic RNAs and that they are, as a rule, shorter than 400 base pairs

${ }^{1}$ Corresponding author.

E-MAIL hernande@cshl.org; FAX (516) 367-6801.

Article and publication are at http://www.genesdev.org/cgi/doi/10.1101/ gad.1018902. (bp). This length limit is consistent with the elongation properties of RNA polymerase III, which recognizes a simple run of $\mathrm{T}$ residues as a termination signal. The genes transcribed by RNA polymerase III encode RNA molecules involved in fundamental metabolic processes, specifically components of the protein synthesis apparatus and components of the splicing and tRNA processing apparatus, as well as RNAs of unknown function. The RNA polymerase III promoters are more varied in structure than the uniform RNA polymerase I promoters, and yet not as diverse as the RNA polymerase II promoters. They have been divided into three main types, two of which are gene-internal and generally TATA-less, and one of which is gene-external and contains a TATA box. Remarkably, we have a good, and in some cases a very detailed, understanding of how RNA polymerase III is recruited to each of these types of promoters. This provides a paradigm of how the same enzyme can be recruited to different promoter structures through different combinations of protein-DNA and protein-protein interactions. Here we summarize our present understanding of the various pathways leading to recruitment of RNA polymerase III. Other recent reviews on RNA polymerase III transcription include those by Geiduschek and Kassavetis (2001) and Huang and Maraia (2001). Reviews on the regulation of RNA polymerase III transcription, which is not covered here, include those by Ghavidel et al. (1999) and Brown et al. (2000).

\section{Structure of RNA polymerase III promoters}

The three types of RNA polymerase III promoters are called types $1-3$. The first RNA polymerase III promoters characterized were those of the Xenopus laevis 5S RNA gene (Bogenhagen et al. 1980; Sakonju et al. 1980), which encodes the small ribosomal RNA, the Adenovirus 2 (Ad2) VAI gene (Fowlkes and Shenk 1980), and various tRNA genes from X. laevis and Drosophila melanogaster (Galli et al. 1981; Hofstetter et al. 1981; Sharp et al. 1981). The 5 S promoter is the only example of a type 1 RNA polymerase III promoter, and the Ad2 VAI and tRNA promoters are typical type 2 promoters. As shown in Figure 1, these promoters are intragenic. The $X$. laevis $5 S$ gene promoter consists of an A box, an intermediate element (IE), and a C box that is conserved in the $5 \mathrm{~S}$ promoters of different species. Together, these elements 

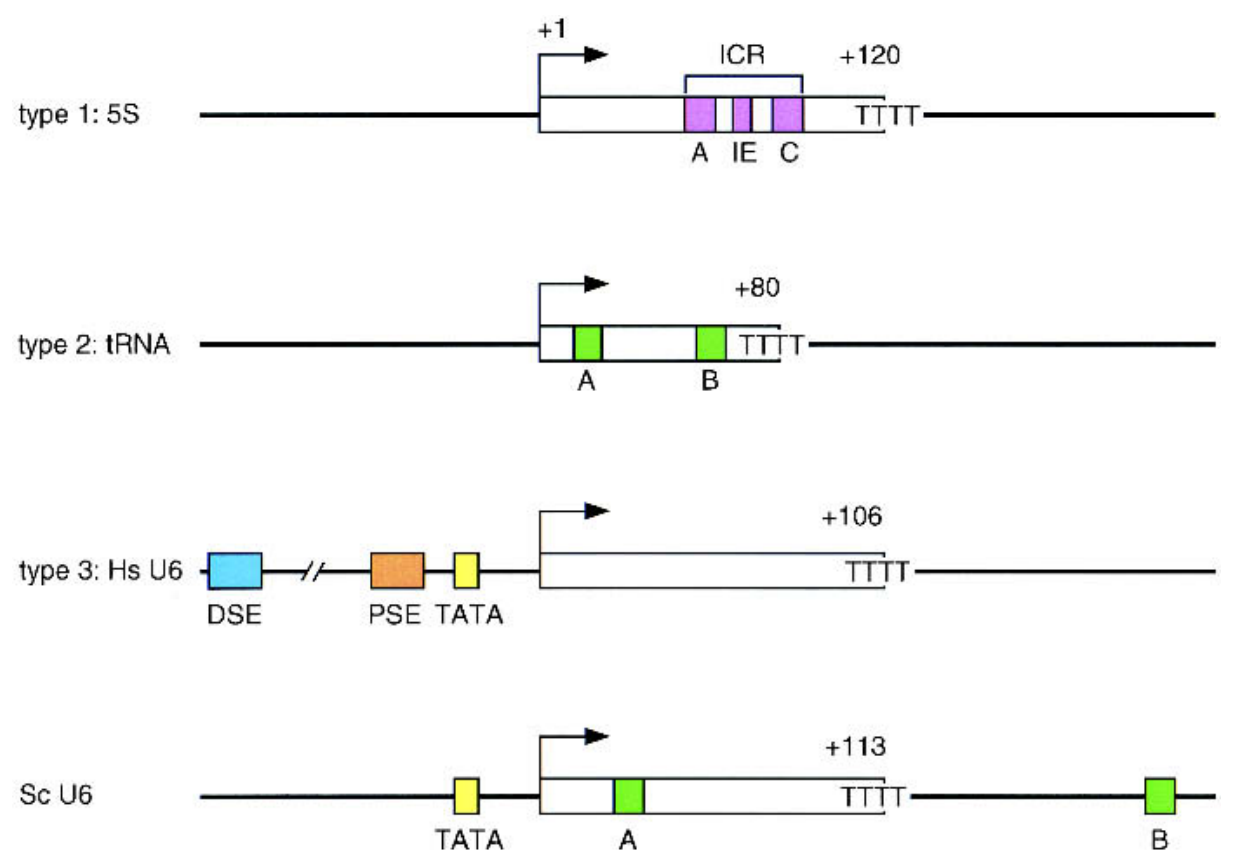

Figure 1. Different types of RNA polymerase III promoters. The type 1 promoter of the Xenopus laevis 5 S RNA gene consists of an internal control region (ICR), which can be subdivided into A box $(+50$ to +60$)$, intermediate element (IE, +67 to +72$)$, and C box $(+80$ to +90$)$. The type 2 promoter of the $X$. laevis tRNA ${ }^{\text {Leu }}$ gene consists of an A box $(+8$ to +19$)$ and a B box $(+52$ to +62$)$. The type 3 promoter of the Homo sapiens U6 snRNA gene consists of a distal sequence element (DSE, -215 to -240 ) that enhances transcription and a core promoter composed of a proximal sequence element (PSE, -65 to -48$)$ and a TATA box (-32 to -25$)$. The Saccharomyces cerevisiae promoter is a hybrid promoter consisting of a TATA box $(-30$ to -23$)$, an A box $(+21$ to +31$)$, and a B box located downstream of the U6 coding region (from +234 to +244 relative to the start site of transcription).

constitute the internal control region (ICR; Bogenhagen 1985; Pieler et al. 1985a,b, 1987). In the Saccharomyces cerevisiae $5 \mathrm{~S}$ genes, only the $\mathrm{C}$ box is required for transcription (Challice and Segall 1989).

The Ad2 VAI and most tRNA promoters consist of an A box and a B box (Galli et al. 1981; Hofstetter et al. 1981; Sharp et al. 1981; Allison et al. 1983). These are well conserved in tRNA genes from various species, probably in part because they encode the tRNA D- and T-loops, which are required for tRNA function. The spacing between the A- and B-boxes varies greatly, however, in part to accommodate introns. The A-boxes of type 1 and 2 promoters are structurally related and are interchangeable in X. laevis (Ciliberto et al. 1983). However, this apparently reflects a similarity in sequence rather than a conserved function, because, as detailed below, the A-boxes of $5 \mathrm{~S}$ and tRNA genes bind different transcription factors (Braun et al. 1992a).

The type 3 core promoters were identified originally in mammalian U6 snRNA genes, which encode the U6 snRNA component of the spliceosome (Krol et al. 1987; Das et al. 1988; Kunkel and Pederson 1988), and in the human 7SK gene (Murphy et al. 1986), whose RNA product has been recently implicated in the regulation of the CDK9/cyclin T complex (Nguyen et al. 2001; Yang et al. 2001). They are also found in, for example, the H1 RNA gene, which encodes the RNA component of human RNase P (Baer et al. 1989), and the gene encoding the RNA component of human RNase MRP (Topper and
Clayton 1990), as well as in genes encoding RNAs of unknown function. Their discovery came as a surprise because, unlike the then-characterized type 1 and 2 promoters, the type 3 core promoters turned out to be geneexternal. As illustrated in Figure 1, they are located in the $5^{\prime}$-flanking region of the gene and consist of a proximal sequence element (PSE), which also constitutes, on its own, the core of RNA polymerase II snRNA promoters, and a TATA box located at a fixed distance downstream of the PSE (Hernandez and Lucito 1988; Mattaj et al. 1988; Kunkel and Pederson 1989; Lobo and Hernandez 1989). Strikingly, in the vertebrate snRNA promoters, RNA polymerase specificity can be switched from RNA polymerase III to RNA polymerase II and vice versa by abrogation or generation of the TATA box (Lobo and Hernandez 1989). Upstream of the PSE is an element referred to as the distal sequence element (DSE), which activates transcription from the core promoter.

Although the presence of a TATA box is the hallmark of type 3 , gene-external, promoters, it is also found in the 5 '-flanking regions of some genes with gene-internal promoter elements. Figure 1 shows an example of such a hybrid promoter, namely the $S$. cerevisiae U6 snRNA promoter. It consists of an A box, a B box located at an unusual position $120 \mathrm{bp}$ downstream of the RNA coding region, and a TATA box located upstream of the transcription start site. All three of these promoter elements are required for efficient transcription in vivo (Brow and Guthrie 1990; Eschenlauer et al. 1993). Other examples 
include some A- and B-box-containing tRNA genes in plants (Yukawa et al. 2000), yeast (Dieci et al. 2000), and silkworm (Ouyang et al. 2000), in which TATA boxes present in the $5^{\prime}$-flanking region greatly contribute to transcription efficiency. More recently, an analysis in Schizosaccharomyces pombe has revealed that in this organism nearly all tRNA and $5 \mathrm{~S}$ genes contain a TATA box upstream of the transcription start site that is required for transcription (Hamada et al. 2001). Strikingly, in vitro, artificial promoters consisting of just a TATA box can direct RNA polymerase III transcription, indicating that under these circumstances, the TATA box contains all necessary information to assemble an RNA polymerase III transcription initiation complex (Mitchell et al. 1992; Roberts et al. 1995; Wang and Stumph 1995; Whitehall et al. 1995; Huang et al. 1996).

The assembly pathways directed by the different types of RNA polymerase III promoters converge on recruitment of TFIIIB and RNA polymerase III

The characterization of RNA polymerase III transcription factors started with the fractionation of a HeLa cell extract over a phosphocellulose column into three fractions known as fractions A (the phosphocellulose 100 $\mathrm{mM} \mathrm{KCl}$ flowthrough), B (a $100 \mathrm{mM}-350 \mathrm{mM} \mathrm{KCl}$ step elution), and C (a $350 \mathrm{mM}-600 \mathrm{mM} \mathrm{KCl}$ step elution), and the observation that transcription from type 2 promoters required fractions $\mathrm{B}$ and $\mathrm{C}$, whereas transcription from type 1 promoters required the three fractions (Segall et al. 1980). After the type 3 promoters were discov- ered, they were shown to require the $\mathrm{B}$ and $\mathrm{C}$ fractions, or the B fraction and a D fraction eluted between 600 $\mathrm{mM}$ and $1000 \mathrm{mM} \mathrm{KCl}$ from the phosphocellulose column (Lobo et al. 1991). Most of the activities in these fractions required for RNA polymerase III transcription have now been characterized, both from yeast and human cells. Figure 2 shows, in a highly simplified manner, how these factors can assemble in an ordered fashion to recruit RNA polymerase III. The green arrows symbolize interactions of DNA-binding proteins with promoter elements, the blue arrows protein-protein contacts among various transcription factors, and the purple arrows protein-protein contacts between RNA polymerase III and transcription factors.

In type 2 promoters, the $\mathrm{A}$ and $\mathrm{B}$ boxes are recognized by a multisubunit complex in the $\mathrm{C}$ fraction called TFIIIC or TFIIIC2 (Lassar et al. 1983). This initial DNAprotein interaction then allows the recruitment of an activity in the B fraction called TFIIIB (Bieker et al. 1985; Setzer and Brown 1985). TFIIIB is composed of three polypeptides, one of which is the TATA-box-binding protein TBP. The binding of TFIIIB to the promoter in turn allows the recruitment of RNA polymerase III, mainly through protein-protein interactions with TFIIIB, although contacts with TFIIIC may also contribute (Fig. 2A). In type 1 promoters, the ICR is recognized by the activity present in the A fraction, a zinc finger protein referred to as TFIIIA (Engelke et al. 1980; Sakonju et al. 1981). Formation of the TFIIIA-DNA complex then allows for the binding of TFIIIC (Lassar et al. 1983). Thus, TFIIIA can be viewed as a specificity factor that

\section{Gene - internal}
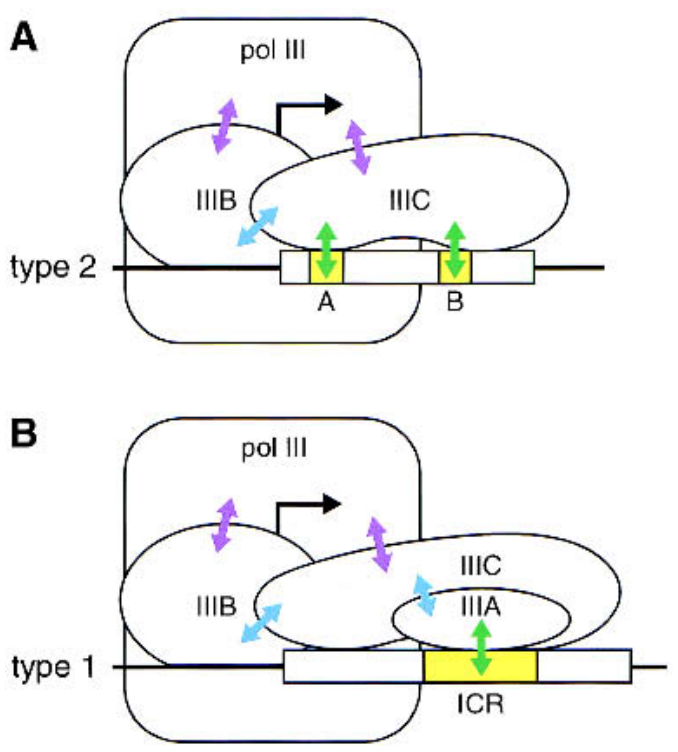

\section{Gene - external}
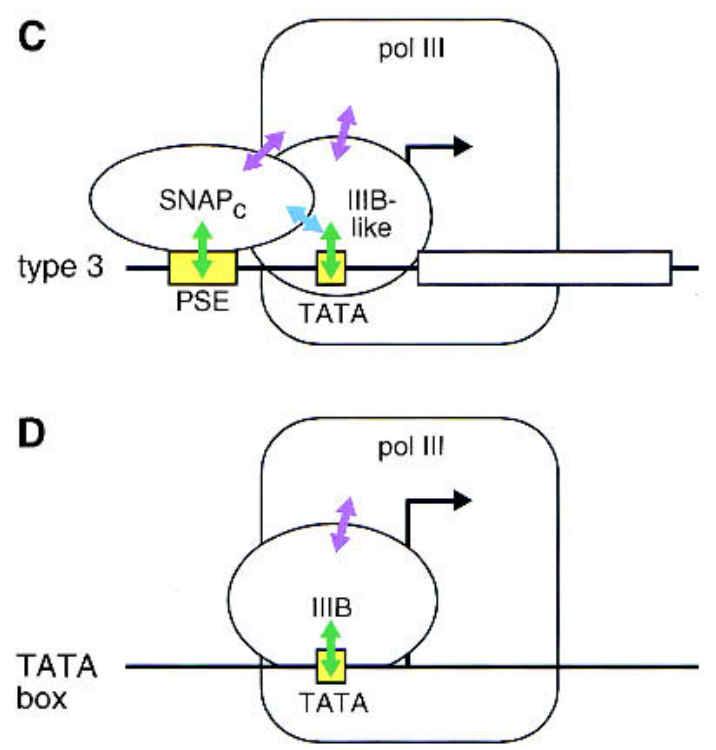

Figure 2. Different pathways for recruitment of TFIIIB and RNA polymerase III. The initiation complexes formed on type 2, 1 , and 3 promoters, as well as on an artificial promoter consisting of just a TATA box, are shown. The green arrows symbolize interactions of DNA-binding proteins with promoter elements, the blue arrows protein-protein contacts among various transcription factors, and the purple arrows protein-protein contacts between RNA polymerase III and transcription factors. 
alters the promoter-recognition properties of TFIIIC and targets it to the $5 \mathrm{~S}$ promoter. After the binding of TFIIIC, the pathway to recruitment of the polymerase is similar to that in type 2 promoters, with the recruitment of TFIIIB and RNA polymerase III (Fig. 2B). In type 3 promoters, the PSE is recognized by a multisubunit complex variously called the PSE-binding protein (PBP), the PSE transcription factor (PTF), or the snRNA activating protein complex $\left(\mathrm{SNAP}_{\mathrm{c}}\right)$, and the TATA box is recognized by the TBP component of a specialized TFIIIB-like activity (Waldschmidt et al. 1991; Murphy et al. 1992; Sadowski et al. 1993; Yoon et al. 1995; Schramm et al. 2000; Teichmann et al. 2000). These DNA-protein interactions are reinforced by protein-protein interactions between SNAP ${ }_{\mathrm{c}}$ and TBP (Mittal and Hernandez 1997; Ma and Hernandez 2002). The binding of $\mathrm{SNAP}_{\mathrm{c}}$ and the TFIIIB-like activity then lead to recruitment of RNA polymerase III (Sepehri Chong et al. 2001), probably through protein-protein contacts with the two DNAbound factors, $\mathrm{SNAP}_{\mathrm{c}}$ and the TFIIIB-like activity, although this has not yet been demonstrated (Fig. 2C).

Figure 2 also shows a recruitment pathway in which TFIIIB is directly recruited to a TATA box without the help of protein-protein contacts with either TFIIIC or $\mathrm{SNAP}_{\mathrm{c}}$ (Fig. 2D). This pathway can be observed in vitro with $S$. cerevisiae TFIIIB, and, although it is not observed in vivo, it reveals a profound aspect of RNA polymerase III transcription, namely, that TFIIIB is sufficient for RNA polymerase recruitment. TFIIIB was first identified as the key RNA polymerase III transcription factor by a series of experiments in which $S$. cerevisiae TFIIIB was first recruited to either a $5 \mathrm{~S}$ promoter through prior binding of TFIIIA and TFIIIC, or a tRNA promoter through prior binding of TFIIIC (Kassavetis et al. 1990). TFIIIA and/or TFIIIC were then stripped from the DNA by treatment with heparin or high concentrations of salt. Under these conditions, functional TFIIIA and TFIIIC were released from the templates, but remarkably, TFIIIB remained bound to the DNA, generating the same footprint upstream of the transcription start site as it did in the presence of TFIIIA and/or TFIIIC (Kassavetis et al. 1989, 1990). These stripped templates were able to support several rounds of properly initiated RNA polymerase III transcription. This suggested that, at least in yeast, TFIIIB was sufficient to recruit RNA polymerase III and direct several rounds of transcription, and therefore that the main function of TFIIIA and TFIIIC was to recruit TFIIIB to the DNA (Kassavetis et al. 1990). With the observation that just a TATA box could direct RNA polymerase III transcription in vitro and with the availability of recombinant TFIIIB, it then became possible to confirm that a TATA box could direct several rounds of RNA polymerase III transcription with just recombinant TFIIIB and highly purified RNA polymerase III (Kassavetis et al. 1995; Rüth et al. 1996). Thus, TFIIIA, TFIIIC, and $\mathrm{SNAP}_{\mathrm{c}}$ can be viewed as recruitment factors whose main function is to recruit TFIIIB to promoters of various structures, which then allows the recruitment of RNA polymerase III.

The different RNA polymerase III promoters offer a unique system in which we know how different accessory factors combine to recruit, ultimately, a TFIIIB activity and RNA polymerase III. Below, we first describe briefly the subunit composition of RNA polymerase III. For a discussion of the likely three-dimensional structure of RNA polymerase III, see Geiduschek and Kassavetis (2001). We then describe the characterization of its key transcription factor, TFIIIB, both yeast and human, and we summarize our present understanding of how this factor bridges DNA and RNA polymerase III. We then summarize what is known about the various factors that, in vivo, mediate the recruitment of TFIIIB on most, if not all, promoters, namely, TFIIIA, TFIIIC, and SNAP . $^{\text {. }}$ We end with a description of some factors that have been implicated in termination and recycling of RNA polymerase III.

\section{RNA polymerase III}

RNA polymerase III is well defined in S. cerevisiae, consisting of 17 subunits, as shown in Table 1 . All the corresponding genes except for RPC37 have been disrupted and shown to be essential (for review, see Chedin et al. 1998). Of the 17 subunits, 10 are unique to RNA polymerase III and are designated the $\mathrm{C}$ subunits, two are common to RNA polymerases I and III and are designated $\mathrm{AC}$ subunits, and five are common to the three RNA polymerases and are designated $\mathrm{ABC}$ subunits. The common subunits have different names in RNA polymerases I and II, as indicated in Table 1 for RNA polymerase II. C160, C128, AC40, AC19, and ABC23 are evolutionarily related to the core subunits of Escherichia coli RNA polymerase, as indicated in parentheses in the table. Of the $\mathrm{C}$ subunits, five, indicated in bold in Table 1 , are specific to RNA polymerase III.

Human RNA polymerase III has been purified both by conventional chromatography (Wang and Roeder 1996) and from cell lines expressing tagged Homo sapiens (Hs) RPC4/RPC53/BN51 (Wang and Roeder 1997), but until recently, only five of its subunits had been characterized: HsRPC4/RPC53 (Ittmann et al. 1993; Jackson et al. 1995), HsRPC1/RPC155 (Sepehri and Hernandez 1997), HsRPC3/RPC62, HsRPC6/RPC39, and HsRPC7/RPC32 (Wang and Roeder 1997). Human RNA polymerase III has now been purified from a stable cell line expressing a doubly tagged HsRPC4 subunit, and its subunits have been identified by mass spectrometry (Hu et al. 2002). This analysis has resulted in the identification of orthologs of all of the yeast RNA polymerase III subunits except for $\mathrm{ABC} 10 \alpha$, which was not detected probably because of its small size $(7 \mathrm{kD})$. The newly described human subunits were named according to the guide shown in the fourth column of Table 1, in which the yeast $\mathrm{C}, \mathrm{AC}$, and $\mathrm{ABC}$ subunits were numbered separately in order of decreasing apparent molecular weight. Such a nomenclature would provide the same name for orthologs from different species, as shown in the fourth and sixth column in Table 1.

The characterization of human RPC8 and RPC9 brought an unexpected result. BLAST searches revealed 
Table 1. Subunits of Saccharomyces cerevisiae and Homo sapiens RNA polymerase III

\begin{tabular}{|c|c|c|c|c|c|c|c|c|}
\hline $\begin{array}{l}\text { S. cerevisiae } \\
\text { RNA Pol III } \\
\text { subunits }\end{array}$ & $\begin{array}{l}\text { MW } \\
(\mathrm{kD})\end{array}$ & $\begin{array}{l}\text { Accession } \\
\text { number }\end{array}$ & $\begin{array}{c}\text { Guide for } \\
\text { nomenclature }\end{array}$ & $\begin{array}{l}\text { Corresponding } \\
\text { S. cerevisiae } \\
\text { RNA Pol II } \\
\text { subunits }\end{array}$ & $\begin{array}{l}\text { H. sapiens RNA } \\
\text { RNA Pol III subunits }\end{array}$ & $\begin{array}{l}\text { MW } \\
(\mathrm{kD})\end{array}$ & Accession number & $\begin{array}{l}\% \text { amino acid } \\
\text { identities between } \\
\text { H. sapiens and } \\
\text { S. cerevisiae } \\
\text { Pol III subunits }\end{array}$ \\
\hline C160 ( $\beta^{\prime}$-like) & 162.1 & P04051 & ScRPCl & RPB1 & HsRPC1/RPC155 & 155.6 & AAB86536 & $50 \%(1356 / 1391)^{a}$ \\
\hline C128 ( $\beta$-like) & 129.3 & AAB59324 & ScRPC2 & RPB2 & HsRPC2 & 127.6 & AY092084 & $63 \%(1115 / 1133)^{a}$ \\
\hline $\mathrm{C} 82$ & 73.6 & CAA45072 & ScRPC3 & & HsRPC3/RPC62 & 60.5 & NP_006459/XP_034604 & $22 \%(163 / 534)^{\mathrm{a}}$ \\
\hline C53 & 46.6 & P25441 & ScRPC4 & & HsRPC4/RPC53 & 44.4 & AY092086 & $28 \%(134 / 398)^{\mathrm{a}}$ \\
\hline C37 & 32.1 & NP_012950 & ScRPC5 & & HsRPC5 & 79.8 & AY092085 & $26 \%(160 / 708)^{a}$ \\
\hline $\mathrm{C} 34$ & 36.1 & P32910 & ScRPC6 & & HsRPC6/RPC39 & 35.6 & NP_006457/XP_009639 & $26 \%(216 / 316)^{a}$ \\
\hline $\mathrm{C} 31$ & 27.7 & P17890 & ScRPC7 & & $\underline{\text { HsRPC7/RPC32 }}$ & 25.9 & AAB63676/XP_036456 & $35 \%(44 / 223)^{\mathrm{a}}$ \\
\hline $\mathrm{C} 25$ & 24.3 & P35718 & ScRPC8 & RPB7 & HsRPC8 & 22.9 & AY092087 & $42 \%(201 / 204)^{\mathrm{a}}$ \\
\hline $\mathrm{C} 17$ & 18.6 & P47076 & ScRPC9 & RPB4 & HsRPC9/CGRP-RC & 16.8 & AAC25992 & $30 \%(122 / 148)^{a}$ \\
\hline C11 & 12.5 & AAD12060 & ScRPC10 & RPB9 & HsRPC10/RPC11 & 12.3 & NP_057394 & $52 \%(108 / 108)^{a}$ \\
\hline AC40 ( $\alpha$-like) & 37.6 & P07703 & ScRPACl & RPB3 & HsRPAC1/RPA5,RPA39 & 38.6 & NP_004866 & $47 \%(287 / 342)^{\mathrm{a}}$ \\
\hline AC19 ( $\alpha$-like) & 16.1 & P28000 & ScRPAC2 & RPB11 & HsRPAC2/RPA9,RPA16 & 15.2 & NP_057056 & $45 \%(119 / 133)^{a}$ \\
\hline $\mathrm{ABC} 27$ & 25.1 & P20434 & ScRPABC1 & RPB5 & HsRPABC1/RPB5,RPB25 & 24.6 & P19388 & $42 \%(207 / 210)^{a}$ \\
\hline ABC23 ( $\omega$-like) & 17.9 & AAA34989 & ScRPABC2 & RPB6 & HsRPABC2/RPB6,RPB14.4 & 14.5 & P41584 & $72 \%(83 / 127)^{\mathrm{a}}$ \\
\hline $\mathrm{ABC} 14.5$ & 16.5 & CAA37383 & ScRPABC3 & RPB8 & HsRPABC3/RPB8,RPB17 & 17.1 & P52434 & $35 \%(147 / 150)^{\mathrm{a}}$ \\
\hline $\mathrm{ABC} 10 \alpha$ & 7.7 & AAA64417 & ScRPABC4 & RPB12 & HsRPABC4/RPB7.0 & 7.0 & P53803 & $52 \%(42 / 58)^{\mathrm{a}}$ \\
\hline $\mathrm{ABC} 10 \beta$ & 8.2 & P22139 & ScRPABC5 & RPB10 & HsRPABC5/RPB10,RPB7.6 & 7.6 & P52436 & $73 \%(67 / 67)^{a}$ \\
\hline
\end{tabular}

Subunits in bold do not have paralogues in RNA polymerases I and II; those in bold and underlined form a complex separable from the rest of the enzyme. Subunits corresponding to the $E$. coli $\beta^{\prime}, \beta, \alpha$, and $\omega$ subunits are indicated. ABC27 and RPB5, ABC23 and RPB6, ABC14.5 and RPB8, ABC10 $\alpha$ and RPB12, $\mathrm{ABC} 10 \beta$ and RPB10 designate in each case the same protein. For HsRPC62, HsRPC39, and HsRPC32, the sequence under the first accession number (Wang and Roeder 1997) differs in several positions from both the sequences deposited by NCBI (second accession number) and genomic sequences.

${ }^{\text {a }}$ The first number in the parentheses indicates the length of the region of similarity; the second number indicates the total length of the human protein. Reprinted from Hu et al. (2002).

that HsRPC8 is related to the RNA polymerase II subunit RPB7, as noted earlier for the S. cerevisiae HsRPC8 ortholog C25 (Sadhale and Woychik 1994). In addition, however, HsRPC9 is related to RPB4, and like RPB4 and RPB7, which associate with each other and form a dimer detachable from the rest of RNA polymerase II (Edwards et al. 1991; Khazak et al. 1998), HsRPC8 and HsRPC9 associate with each other (Hu et al. 2002). This strongly suggests that HsRPC8 and HsRPC9 are paralogs of RPB7 and RPB4, as indicated in Table 1, and that the corresponding $S$. cerevisiae RNA polymerase III subunits C25 and $\mathrm{C} 17$ can similarly associate with each other.

RPB7, but not RPB4, is essential for yeast cell viability (Woychik and Young 1989; McKune et al. 1993). RPB4 is, however, essential for cellular responses to stress (Choder and Young 1993) and thus in vivo, the requirement for the RPB4 subunit may be promoter-specific. The RPB4/RPB7 complex is thought to stabilize the open promoter complex and perhaps the early transcribing complex prior to promoter escape by binding to nascent RNA or to single-stranded DNA in the transcription bubble (Orlicky et al. 2001; Todone et al. 2001). The $S$. cerevisiae RNA polymerase III paralogs of RBP7 and RPB4, C25 and C17, are both essential for viability in yeast (Sadhale and Woychik 1994; Ferri et al. 2000). Twohybrid and coimmunoprecipitation experiments indicate that $\mathrm{C} 17$ interacts with the transcription initiation factor Brf1 and with the RNA polymerase III C31 subunit (Ferri et al. 2000), which, as described below, is itself required for transcription initiation (Werner et al. 1992, 1993; Wang and Roeder 1997). Thus, the RNA polymerase III paralogs of RPB4 and RPB7 may also be involved in transcription initiation, but in this case both subunits are essential for yeast cell viability, perhaps because most RNA polymerase III genes encode components essential for cell metabolism.

The human RNA polymerase III subunits are in general quite similar to their yeast counterparts with the notable exception of the subunits with no paralogs in RNA polymerase II (Jackson et al. 1995; Wang and Roeder 1997; Hu et al. 2002). For example, the human ortholog of yeast C37 is an $80-\mathrm{kD}$ protein, HsRPC5, whose similarity to the yeast protein is confined to its N-terminal fourth, which shows $26 \%$ identity with C37 (Hu et al. 2002). Nevertheless, like yeast C37, which associates with the yeast C53 subunit (Flores et al. 1999), HsRPC5 associates with HsRPC4/RPC53, the human ortholog of yeast C53, and this association is through the HsRPC5 and HsRPC4/RPC53 domains conserved in their yeast counterparts (Hu et al. 2002). Interestingly, at least some of the subunits with no paralogs in RNA polymerase II seem to be involved in promoter recognition. The C82, C34, and C31 subunits (bold and underlined in Table 1) dissociate from a yeast enzyme carrying a mutation within the zinc finger domain of the largest subunit, and each associates with the two others in a yeast two-hybrid assay, suggesting that these three subunits form a subcomplex detachable from the rest of the enzyme (Werner et al. 1992, 1993). In the human enzyme, such a subcomplex could be demonstrated directly by sucrose gradient centrifugation under partially denaturing conditions and by reconstitution of the subcomplex from recombinant subunits (Wang and Roeder 1997). The subunits in the subcomplex are not required for ef- 
ficient elongation and termination, but are required for specific initiation (Thuillier et al. 1995; Brun et al. 1997; Wang and Roeder 1997). Consistent with this observation and as detailed further below, the C34 subunit and its human counterpart interact directly with TFIIIB subunits (Werner et al. 1993; Khoo et al. 1994; Wang and Roeder 1997).

\section{Composition of TFIIIB}

$T B P$ is required for transcription by RNA polymerase III both in S. cerevisiae and human cells

Although the presence of an RNA polymerase III transcription activity in the phosphocellulose B fraction was recognized in the early 1980s, the composition of this activity remained a mystery for the next 10 years. By the late 1980s, however, the concept that the TATA-boxbinding protein TBP was a factor uniquely dedicated to transcription by RNA polymerase II began to change with the finding that an essential element of the U6 promoter was an A/T-rich region, that is, a potential binding site for TBP. Biochemical fractionation and reconstitution experiments then identified TBP as a factor required for transcription of both the yeast and human U6 snRNA genes (Lobo et al. 1991; Margottin et al. 1991; Simmen et al. 1991), whose binding to wild-type and mutant U6 TATA boxes correlated with transcription activity (Lobo et al. 1991). These findings established that TATA boxes are part of at least some RNA polymerase III promoters, and that they act by recruiting TBP. They also raised the possibility that TBP might be required for RNA polymerase III transcription in general. Indeed, in vitro competition experiments with TATAcontaining oligonucleotides then indicated that a TATAbox-binding factor was required for transcription of the VAI and tRNA genes (White et al. 1992), and inactivation of TBP in yeast was shown to lead to defects in transcription by all three RNA polymerases (Cormack and Struhl 1992; Schultz et al. 1992). The remaining question was how to place TBP in what was then known about RNA polymerase III transcription factors.

\section{Identification of S. cerevisiae Brf1 and Bdp1}

Yeast TFIIIB had been shown to consist of two chromatographically separable activities, named $\mathrm{B}^{\prime}$ and $\mathrm{B}^{\prime \prime}$, which contained polypeptides of 70 and $90 \mathrm{kD}$, respectively, that could be cross-linked to the DNA (Bartholomew et al. 1991; Kassavetis et al. 1991). A major step in the complete characterization of TFIIIB came with the cloning of the gene encoding the $70-\mathrm{kD}$ polypeptide, now referred to as Brf1 (TFIIB-related factor $\underline{1}$; for a description of a universal nomenclature of TFIIIB components, see Willis 2002). The gene was cloned as a suppressor of a tRNA gene A-box mutation and called PCF4 (López-De-León et al. 1992). It was also cloned, however, as an allele-specific high-copy suppressor of certain mutations in TBP and called BRF1 (Colbert and Hahn 1992) or TDS4 (Bu- ratowski and Zhou 1992). This ability to suppress mutations in TBP suggested that Brf1 might be associated with TBP, and thus that TBP might be part of the TFIIIB activity. Indeed, TBP was shown to be part of both the yeast and mammalian TFIIIB activity by biochemical methods (Margottin et al. 1991; Huet and Sentenac 1992; Kassavetis et al. 1992; Lobo et al. 1992; Taggart et al. 1992; White and Jackson 1992; Chiang et al. 1993; Meyers and Sharp 1993), and to constitute a previously unrecognized, Brf1-associated, component of the $\mathrm{B}^{\prime}$ activity (Kassavetis et al. 1992). The cloning of the gene encoding yeast B" (B", Kassavetis et al. 1995; TFIIIB90, Roberts et al. 1996; TFC7p, Rüth et al. 1996), now referred to as $B d p 1$ (B double prime 1 , Willis 2002), then completed the characterization of $S$. cerevisiae TFIIIB.

\section{Identification of human Brf1 and Brf2}

In $S$. cerevisiae, all RNA polymerase III promoters recruit the same TFIIIB factor (Joazeiro et al. 1994). In higher eukaryotes, however, the situation is more complex, consistent with the need to transcribe much more complex genomes. Thus, the initial characterization of mammalian TFIIIB not only indicated that TBP was part of the activity (Lobo et al. 1992; Taggart et al. 1992; White and Jackson 1992), but also that type 1 and 2 promoters used different components in the TFIIIB fraction than type 3 promoters. Type 1 and 2 promoters were shown to require a TBP-containing complex (Lobo et al. 1992; Teichmann and Seifart 1995) consisting of TBP and a homolog of yeast Brf1 (Wang and Roeder 1995; Mital et al. 1996) referred to as HsBrf1 (ㅂomo sapiens Brf1). Depletion of extracts with antibodies directed against the C-terminal half of HsBrf1 debilitated transcription from the type 2 VAI promoter, as expected, but had no effect on transcription from the type 3 human U6 snRNA promoter (Mital et al. 1996; Henry et al. 1998a). On the other hand, depletion of extracts with antibodies raised against full-length HsBrf1 or against a peptide derived from the $\mathrm{N}$-terminal portion of the protein inhibited transcription from all types of RNA polymerase III promoters, although only transcription from type 1 and 2 promoters could be reconstituted by addition of recombinant HsBrf1 (Wang and Roeder 1995; Schramm et al. 2000). These observations suggested that type 3 promoters use a protein related to Brf1 in its $\mathrm{N}$-terminal but not its C-terminal region, and led to the characterization of a new protein, originally called BRFU (Schramm et al. 2000) or TFIIIB50 (Teichmann et al. 2000), and now referred to as HsBrf2 (Willis 2002). Thus, S. cerevisiae Brf1 has at least two homologs in human cells, HsBrf1 and HsBrf2.

Figure 3 shows the structure of TFIIB and various Brf proteins. H. sapiens and S. cerevisiae $(\mathrm{Sc}) \mathrm{Brf1}$ as well as HsBrf2 contain, like TFIIB, an N-terminal zinc-binding domain (green box) and a "core domain" consisting of two imperfect repeats (blue box). In addition, the Brf1 and Brf2 proteins contain C-terminal domains absent in TFIIB. Within the C-terminal segment of Brf1, three regions, designated regions I, II, and III, are conserved in 


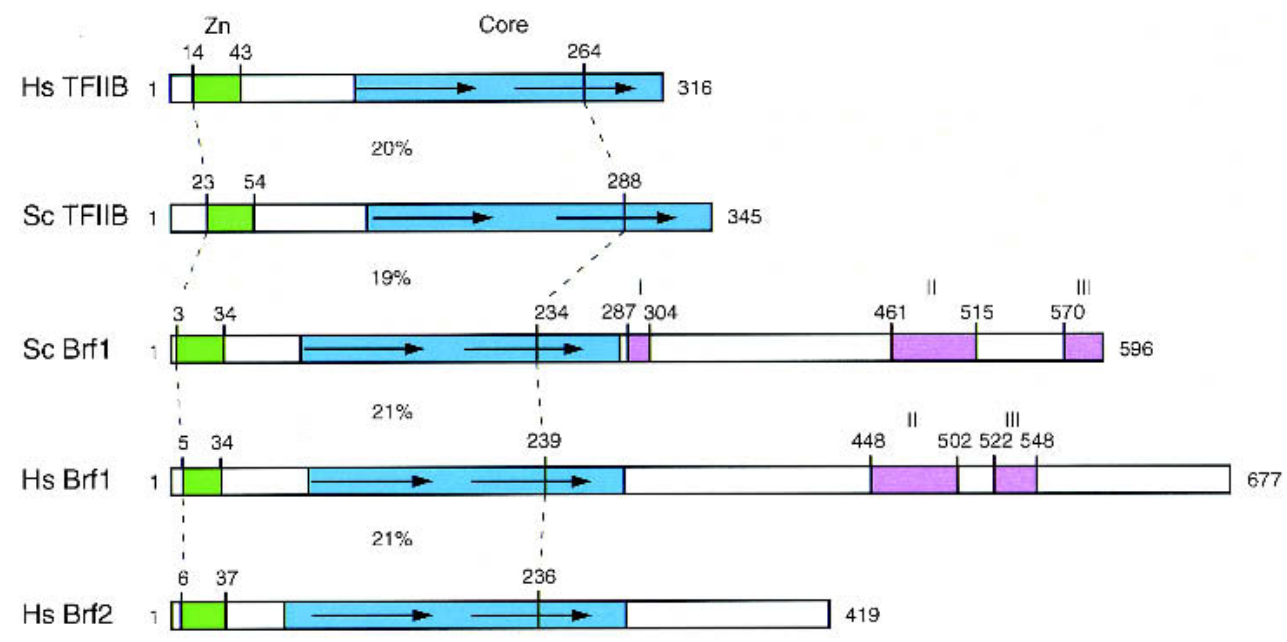

Hs Brf1 v2

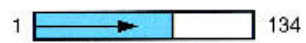

Figure 3. TFIIB, Brf1, and Brf2 form a family of related transcription factors. The location of the structured zinc ribbon as modeled in ScTFIIB and ScBrf1 (Hahn and Roberts 2000) based on the NMR structure of PfTFIIB (Zhu et al. 1996) and that of the corresponding region in HsBrf1 and HsBrf2 is indicated in green. The location of the structured core domain of TFIIB (Bagby et al. 1995; Nikolov et al. 1995) and that of the corresponding regions in the other proteins is indicated in blue. The percentages below the sequences indicate percent identities between HsBrf2 and HsTFIIB, ScTFIIB, ScBrf1, and HsBrf1 within the region of highest conservation (bracketed by the stippled lines) in pairwise alignments performed with BLAST. The purple boxes in the C-terminal regions of ScBrf1 and HsBrf1 indicate conserved regions I, II, and III (Mital et al. 1996). In HsBrf1_v2, the blue region is identical to the corresponding HsBrf1 region.

the yeasts Candida albicans, Kluyveromyces lactis, $S$. pombe, and S. cerevisiae (Khoo et al. 1994). Regions II and III are also conserved in the human Brf1 protein (Mital et al. 1996; Andrau et al. 1999). Consistent with the antibody depletion data, the C-terminal domain of HsBrf2 shows very little, if any, homology with Brf1.

HsBrf2 was isolated through a database search for proteins related to TFIIB and to the TFIIB-related segment of Brf1 (Schramm et al. 2000), as well as through biochemical purification of a complex, consisting of HsBrf2 and four associated proteins, required for transcription from type 3 promoters (Teichmann et al. 2000). It is clear that HsBrf2 itself is specifically required for transcription from type 3, but not types 1 and 2, promoters, but the exact role of the HsBrf2-associated factors remains to be determined. Although in one case, U6 transcription in HsBrf2-depleted extracts could be restored only by addition of the HsBrf2-containing complex immunopurified from HeLa cells expressing tagged HsBrf2 (Teichmann et al. 2000), in another case it could be restored by addition of just HsBrf2 synthesized in E. coli (Schramm et al. 2000). This last observation suggests that the HsBrf2associated polypeptides may not be absolutely required for U6 transcription but may contribute to the efficiency of the reaction.

Figure 3 also illustrates the structure of HsBrf1_v2 (originally named BRF2), a factor encoded by one of at least four alternatively spliced BRF1 pre-mRNAs (McCulloch et al. 2000). HsBrf1_v2 lacks the zinc finger domain and the first repeat that are present in Brf1 and conserved in the other proteins of the TFIIB family, as well as the C-terminal region present in Brf1. Although HsBrf1 is not involved in human U6 transcription, HsBrf1_v2 has been implicated in U6 transcription because when antibodies recognizing all HsBrfl variants were used to deplete extracts, U6 transcription was lost and could be specifically restored by addition of material immunopurified from cells expressing tagged HsBrf1_v2 (McCulloch et al. 2000). It will be necessary to define the composition of this immunopurified fraction to confirm the role of HsBrf1_v2 in U6 transcription.

\section{Identification of human $B d p 1$}

Figure 4 shows the structure of $S$. cerevisiae Bdp1. It contains a domain related to a Myb repeat, identified in the SWI-SNF and ADA complexes, the transcriptional corepressor $\underline{\mathrm{N}}$-Cor, and yeast TFIIIB Bdp1, and therefore referred to as the SANT domain (Aasland et al. 1996). The SANT domain is absolutely required for TFIIIC-dependent (but not TFIIIC-independent, see below) RNA polymerase III transcription (Kumar et al. 1997). In addition, a region upstream of the SANT domain (indicated in orange in Fig. 4) is required for transcription from linear, but not supercoiled, templates (Kassavetis et al. 1998a).

Human Bdp1 cDNAs were isolated through a combination of database searches for sequences similar to the yeast Bdp1 SANT domain and library screening (Schramm et al. 2000). The structure of the protein encoded by one of these cDNAs (HsBdp1) is shown in Figure 4. It is highly related to the yeast protein within the 


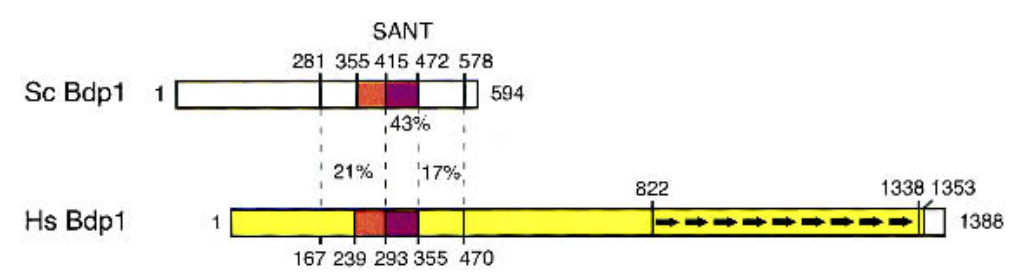

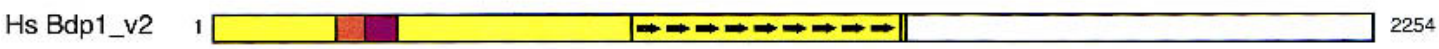

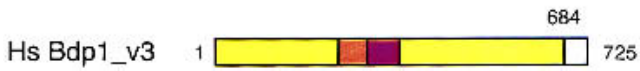

Figure 4. Comparison of the ScBdp1 and HsBdp1 polypeptides. The proteins contain a conserved SANT domain (brown box). The regions upstream and downstream of the SANT domain are also quite conserved, especially a segment upstream of the SANT domain (indicated in orange) that is required for transcription from linear, but not supercoiled, templates. The percentages indicate amino acid identities between ScBdp1 and HsBdp1 in the regions bracketed by dotted lines. HsBdp1, HsBdp1_v2, and HsBdp1_v3 are identical in the colored regions. The repeats extend from amino acids 822 to 1338. HsBdp1 and HsBdp1_v2 diverge after amino acid 1353. HsBdp1 and HsBdp1_v3 diverge after amino acid 684.

SANT domain (43\% identity) as well as both immediately upstream, in a region that encompasses the segment required for transcription from linear DNA templates ( $21 \%$ identity), and downstream ( $17 \%$ identity). Outside of these regions, the two proteins are not conserved, and the human protein differs from the yeast protein by a striking $\mathrm{C}$-terminal extension containing a number of repeats with potential phosphorylation sites. A number of alternatively spliced BDP1 cDNAs have been isolated (Kelter et al. 2000; Schramm et al. 2000). Two of these encode strikingly different proteins, which are also shown in Figure 4. The longest protein (labeled HsBdp1_v2 in the figure) is identical to Bdp1 except that the last few amino acids are replaced by a 901-aminoacid extension, giving a protein of 2254 amino acids. Another cDNA encodes a 725-amino-acid protein (Bdp1_v3), which contains Bdp1 sequences up to amino acid 684 , followed by a divergent 47 -amino-acid extension (Kelter et al. 2000).

Which of the alternatively spliced forms of human Bdp1 are involved in RNA polymerase III transcription in vivo is not clear at present. Depletions of extracts with antibodies directed against regions both upstream and downstream of the SANT domain within the N-terminal half of human Bdp1 (Schramm et al. 2000), as well as against the repeat region (L. Schramm and N. Hernandez, unpubl.), debilitate transcription from both type 2 and 3 promoters in vitro, and transcription can be restored by addition of recombinant human Bdp1, either full-length or truncated downstream of the SANT domain. This suggests that HsBdpl is generally required for RNA polymerase III transcription, and that the $\mathrm{C}$-terminal repeats are not required for basal in vitro transcription from naked DNA templates. However, the functional protein present in HeLa cell extracts probably contains the repeat region, because it can be depleted by antibodies directed against this region. Perhaps the repeat region performs a regulatory role not scored in the in vitro transcription assay.
The characterization of human TFIIIB has revealed that unlike in $S$. cerevisiae, where type 3 promoters apparently do not exist and one form of TFIIIB serves all RNA polymerase III promoters (Joazeiro et al. 1994), there are at least two forms of TFIIIB in human cells. As shown in Figure 5, one of them consists of HsTBP, HsBrfl, and HsBdpl and is used by type 2 (and probably type 1) promoters. The other consists of HsTBP, HsBrf2, and HsBdp1, and is used by type 3 promoters. Future work may reveal that different spliced variants of Bdp1 are recruited to different RNA polymerase III promoters in vivo. Furthermore, in D. melanogaster cells, the TBP in TFIIIB is replaced by a TBP-related factor called TRF1 (Takada et al. 2000). Thus, there may be a wide range of TFIIIB activities in different species containing variants of each of the three TFIIIB components.

In S. cerevisiae, $H$. sapiens, and D. melanogaster, Brf1 is tightly associated with TBP or TRF1 in solution, as symbolized by red bars in Figure 5. On the other hand, Bdp1 is weakly associated with the TBP-Brf1 complex in S. cerevisiae, and very weakly, if at all, in human cells (Kassavetis et al. 1991; Wang and Roeder 1995; Mital et al. 1996; Schramm et al. 2000). Indeed, an association between HsBdp1 and HsTBP can only be detected in GST pull-downs (blue bars in Fig. 5; Cabart and Murphy 2002). Similarly, although HsBrf2 can be shown to associate with HsTBP in GST pull-downs (Cabart and Murphy 2001, 2002), it is not strongly associated with TBP in HeLa cell extracts (Schramm et al. 2000). Thus, the TFIIIB components do not always form a stable complex off the DNA.

\section{Functions of TFIIIB}

In RNA polymerase II transcription, the opening of the transcription bubble that occurs after recruitment of the polymerase is dependent on TFIIE and an ATP-dependent helicase activity of TFIIH (Holstege et al. 1996; Tirode et al. 1999). In contrast, in RNA polymerase III 


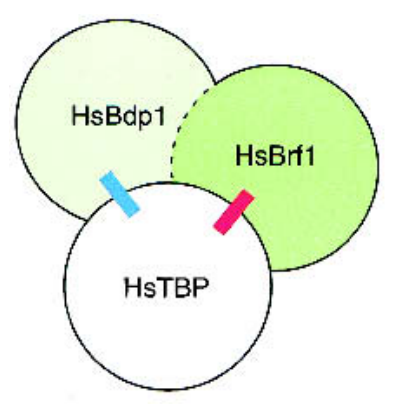

Type 1,2

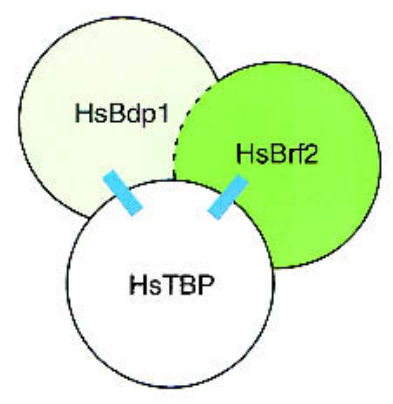

Type 3

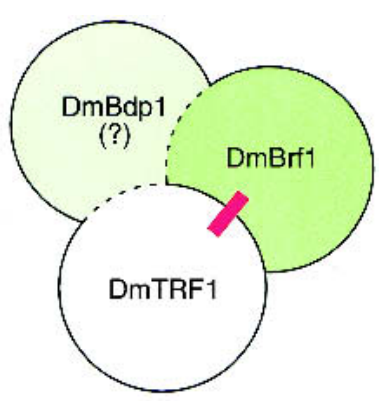

Type 1,2,3

Figure 5. Promoter-selective TFIIIB activities. The TFIIIB components required by different classes of promoters in Homo sapiens and Drosophila melanogaster are depicted. Strong (red bars) and weak (blue bars) direct protein-protein associations in solution are indicated. Stippled lines indicate that a direct protein-protein contact has not been demonstrated. DmBdp1 has not been characterized, but a candidate gene has been identified (Schramm et al. 2000).

transcription, the opening of the transcription bubble occurs in an ATP-independent manner after recruitment of RNA polymerase III by TFIIIB (Kassavetis et al. 1990, 1992). The availability, in yeast, of both recombinant TFIIIB and a transcription system independent of TFIIIC, that is, a system in which a TATA box can recruit TFIIIB directly, has allowed detailed analyses of the functions of the TFIIIB subunits. These studies have given a detailed picture of how TFIIIB recognizes the TATA box and how it recruits RNA polymerase III. They have also revealed that, remarkably, TFIIIB not only functions to recruit RNA polymerase III but also participates in opening of the transcription bubble.

\section{Binding of TFIIIB to the TATA box}

In promoters consisting of just a TATA box, S. cerevisiae TFIIIB binds to the DNA through recognition of the TATA box by its TBP subunit. Indeed, a mutation in the TATA box that debilitates RNA polymerase III transcription can be compensated by a mutation in TBP that alters the DNA-binding specificity of the protein and allows it to bind to the mutated TATA box (Strubin and Struhl 1992; Whitehall et al. 1995). The TBP-TATA-box complex is then recognized by Brf1 or, in the case of the human U6 promoter, by Brf2. The similarity of both Brf1 and Brf2 to TFIIB is very striking, and immediately suggests that the conserved domains of these proteins may perform equivalent functions during assembly of RNA polymerase II and III transcription initiation complexes. The reality, however, is more complex. In TFIIB, the core domain is sufficient for association with the TATA-boxTBP complex. However, recruitment of RNA polymerase II and TFIIF to the TATA-box-TBP-TFIIB complex requires the TFIIB zinc-binding domain (Barberis et al. 1993; Ha et al. 1993; Hisatake et al. 1993; Yamashita et al. 1993; Pardee et al. 1998).

HsBrf2 resembles TFIIB in that it recognizes the TATA-box/TBP complex through its TFIIB-related core domain (Cabart and Murphy 2001). In contrast, for $S$. cerevisiae Brf1, the task of recognizing the TBP-TATAbox complex is performed by two regions of the protein, the TFIIB-related N-terminal half as well as the Brf1specific C-terminal half, with the latter playing the major role. Thus, as summarized in Figure 6, a truncated

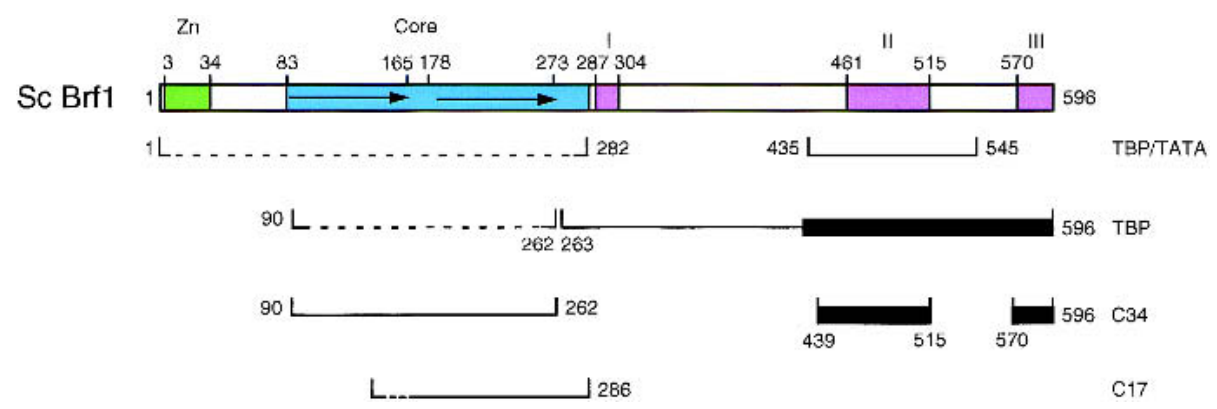

Figure 6. Functional domains of Saccharomyces cerevisiae Brf1. S. cerevisiae Brf1 is depicted, with the locations of the zinc domain, direct repeats in the core, and conserved regions I, II, and III. The brackets below indicate regions of the proteins sufficient for association with the TBP-TATA-box complex (Kassavetis et al. 1998b), TBP alone (Khoo et al. 1994), and the C34 (Khoo et al. 1994; Andrau et al. 1999) and C17 (Ferri et al. 2000) subunits of RNA polymerase III. The black boxes indicate regions where mutations or deletions have a strong negative effect on the associations. The stippled line indicates an association detected only by UV crosslinking. The upstream boundary of the Brf1 region sufficient for interaction with $\mathrm{C} 17$ is not precisely defined. 
ScBrf1 protein retaining just the zinc-binding domain and the core associates only very weakly with a TATAbox-TBP complex. Indeed, the association is so weak that it is only detected by methods such as photochemical cross-linking (Kassavetis et al. 1997, 1998b; Colbert et al. 1998). This weak association appears to involve a TBP surface that overlaps or lies near the TFIIB-interacting surface in the "stirrup" of the second TBP repeat, because a triple-amino-acid change in TBP that disrupts the TFIIB interaction suppresses cross-linking of the $\mathrm{N}$ terminal half of ScBrfl to DNA and thus probably association with the TBP-TATA-box complex (Kassavetis et al. 1998b). On the other hand, a 110-amino-acid region encompassing conserved region II within the C-terminal half of the protein is sufficient for stable association with a TATA-box-TBP complex as well as for recruitment of ScBdp1. Moreover, the hydroxyl radical footprint observed with just the C-terminal domain of ScBrf1 is identical to that observed with the full-length protein /Colbert et al. 1998). Thus, despite the strong conservation of the core domains in TFIIB and Brf1, it appears that in ScBrf1, the function of recognizing the TBP-TATA-box complex has been largely transferred to the C-terminal half of the protein and in particular to conserved region II. This region of ScBrf1 binds the opposite face of the TBP-TATA-box complex from TFIIB and recognizes a TBP surface that overlaps that recognized by TFIIA /Colbert et al. 1998; Kassavetis et al. 1998b; Shen et al. 1998; for models of the structure of the TBP-DNA-ScBrf1 complex, see Colbert et al. 1998; Geiduschek and Kassavetis 2001). It will be important to contrast HsBrf1 and HsBrf2 with ScBrf1 to determine how these TBP-association activities have been conserved among the human Brf1 and Brf2 proteins.

ScBdp1 can associate with a preassembled TBPScBrf1-TATA-box complex but not with a complex lacking ScBrf1, and this confers on the yeast TFIIIB-DNA complex its striking resistance to salt and heparin. ScBdp1 contacts not only ScBrf1 but also TBP, because at least one mutation in yeast TBP prevents association of ScBdp1 without affecting association of ScBrf1 /Colbert et al. 1998). ScBdp1 also contacts DNA because its assembly onto the TATA-box-TBP-ScBrf1 complex both requires DNA, and extends the DNA footprint, upstream of the TATA box (Colbert et al. 1998; Shah et al. 1999). Moreover, ScBdp1 can be cross-linked to the DNA at sites upstream of the TATA box (Shah et al. 1999). The binding of ScBdp1 to the TBP-ScBrf1-TATA-box complex induces a bend in the DNA between the TATA box and the transcription start site, which is in phase with the bend imposed by TBP on the TATA box (Leveillard et al. 1991; Braun et al. 1992b; Grove et al. 1999). This bending of the DNA has been postulated to contribute to the ScBdp1-dependent stabilization of the TFIIIIB-DNA complex by helping impede sliding of the DNA out of the complex (Grove et al. 1999), a hypothesis consistent with thermodynamic and kinetic data indicating ScBdp1-dependent kinetic trapping of the DNA (Cloutier et al. 2001). In the human system, HsBdp1 has been shown to assemble, albeit inefficiently, on a preformed
TATA-box-TBP-HsBrf2 complex (Cabart and Murphy 2002).

\section{RNA polymerase recruitment by TFIIIB}

Figure 7 shows the known protein-protein contacts between TFIIIB and RNA polymerase III subunits with arrows for contacts identified with human (solid) or yeast (hatched) subunits, respectively. Eight RNA polymerase III subunits can be cross-linked to DNA in a transcription initiation complex (Bartholomew et al. 1993). Of these, C34, which is part of the three-subunit subcomplex that is required for transcription initiation (Werner et al. 1993; Wang and Roeder 1997), maps the furthest upstream and can be localized between positions -17 and +6 relative to the transcription start site, in close proximity to TFIIIB (Bartholomew et al. 1993). ScBrf1 interacts in vivo and in vitro with $\mathrm{C} 34$, and human Brf1 associates with the human homolog of C34, HsRPC39, in vitro (Werner et al. 1993; Khoo et al. 1994; Wang and Roeder 1997). As shown in Figure 6, ScBrf1 appears to contact C34 through three regions: regions II and III within the Brf1-specific C-terminal domain (Andrau et al. 1999|, and another region, identified by GST pulldown assays, located within the core region in the TFIIBrelated N-terminal half of the protein (Khoo et al. 1994). ScBrf1 also contacts the recently identified RNA polymerase III subunit $\mathrm{C} 17$ through the $\mathrm{C}$-terminal half of its core region (Ferri et al. 2000). Notably, unlike the zincbinding domain of TFIIB, the zinc-binding domain of ScBrfl is not required for RNA polymerase recruitment (Kassavetis et al. 1997; Hahn and Roberts 2000). How HsBrf2 contacts RNA polymerase III is not known. It will be highly interesting to determine further which parts of the protein are required for assembly with TBP and $\mathrm{SNAP}_{\mathrm{c}}$ onto the human $\mathrm{U} 6$ promoter and for recruitment of RNA polymerase III. Contacts between Bdpl and RNA polymerase III subunits have not been described, but as shown in Figure 7, human TBP associates

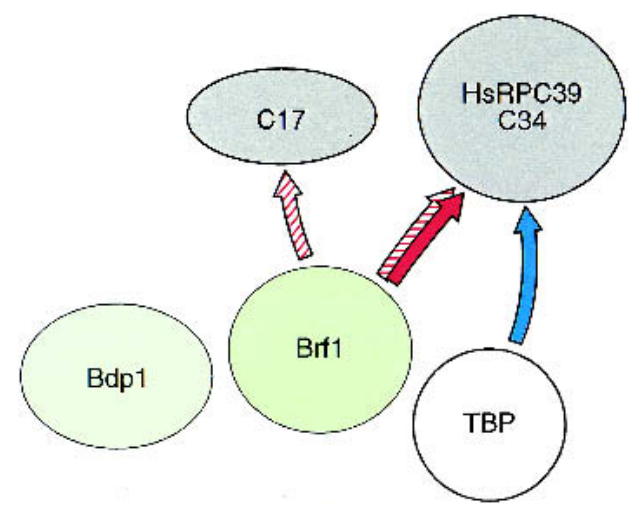

Figure 7. Protein-protein contacts between TFIIIB components and RNA polymerase III subunits. The solid arrows represent contacts identified with human subunits, the stippled arrows depict contacts identified with Saccharomyces cerevisiae subunits. 
with the HsRPC39 RNA polymerase III subunit in vitro (Wang and Roeder 1997).

\section{Post-RNA polymerase III recruitment roles for Brf1 and $B d p 1$}

In in vitro transcription assays with supercoiled templates, the activities of $S$. cerevisiae Brf1 and Bdp1 are surprisingly resistant to deletions. The $\mathrm{N}$-terminal half of ScBrfl forms an unstable TFIIIB complex but is nevertheless capable of directing TFIIIC-independent transcription from a TATA box if high amounts of ScBdp1 are supplied (Kassavetis et al. 1997). The C-terminal half on its own shows little or no transcription activity, but when the N-terminal half of ScBrfl is added in trans, peptides encompassing region II mediate high levels of transcription. Perhaps most surprising, an ScBrf1 protein lacking the first 164 amino acids including the zincbinding domain and the first TFIIB-related repeat retains up to $25 \%$ of the activity of full-length ScBrf1 for TFIIICindependent transcription from supercoiled templates in vitro (Kassavetis et al. 1997). Importantly, however, none of these ScBrfl truncations function in vivo or for TFIIIC-dependent transcription in vitro. Moreover, they do not function for TFIIIC-independent transcription in vitro from a linear template, suggesting that they are somehow defective in promoter opening. Indeed, with the ScBrfl protein lacking the first 164 amino acids, RNA polymerase III is recruited on a linear template, but the transcription bubble does not form (Kassavetis et al. 1998a). This is probably caused at least in part by the absence of the ScBrf1 zinc ribbon, because point mutations within the zinc domain show defects in promoter opening as determined by sensitivity to potassium permanganate (Hahn and Roberts 2000). Therefore, in ScBrf1, the zinc ribbon, which is not required for polymerase recruitment, plays a role at a later stage, during promoter opening.

The ScBdp1 TFIIIB subunit also plays a post-RNA polymerase III recruitment role. Thus, ScBdp1 molecules lacking the conserved region upstream of the SANT domain (see Fig. 4) can direct somewhat reduced levels of transcription from supercoiled templates but are inactive with linear templates and fail to generate permanganate sensitivity around the transcription start site (Kassavetis et al. 1998a). Moreover, ScBdp1 is dispensable for transcription altogether under conditions in which promoter opening is not required (Kassavetis et al. 1999). Upon recruitment of RNA polymerase III, the SUP4 tRNA gene promoter opens in two segments, one surrounding the transcription start site and the other located $\sim 7$ bp upstream (Kassavetis et al. 1992). With templates containing preformed bubbles extending from -9 to -5 , TBP and ScBrfl alone are sufficient to recruit RNA polymerase III and direct multiple rounds of transcription, although the efficiency is only $5 \%$ to $10 \%$ of that observed with the complete TFIIIB complex. Thus, ScBdp1 plays an essential role in promoter opening.

\section{Recruitment factors: TFIIIA}

In an in vitro system in which TFIIIB can be recruited directly to a TATA box, TFIIIB on its own is sufficient to recruit RNA polymerase III. In natural RNA polymerase III promoters, however, TFIIIB is recruited to the DNA in large part through protein-protein contacts with promoter-bound recruitment factors, specifically TFIIIC or $\mathrm{SNAP}_{\mathrm{c}}$. The type $15 \mathrm{~S}$ promoters and type 2 promoters both use TFIIIC, but on the $5 \mathrm{~S}$ promoters TFIIIC is recruited through the specificity factor TFIIIA. TFIIIA is the founding member of the $\mathrm{C}_{2} \mathrm{H}_{2}$ zinc finger family of DNA-binding proteins (Miller et al. 1985) and contains nine $\mathrm{C}_{2} \mathrm{H}_{2}$ zinc fingers. In $S$. cerevisiae, the only essential role of TFIIIA is in the transcription of the 5S RNA genes, because strains engineered to express the 5S rRNA from a tRNA-type promoter and lacking TFIIIA are viable (Camier et al. 1995). This may explain in part the rapid evolution of TFIIIA: TFIIIA sequences from various organisms are poorly conserved, even among vertebrates. As an example, human and X. laevis TFIIIAs share $61 \%$ identity over a 264-amino-acid region-of 423 and 344 amino acids for the human (Arakawa et al. 1995) and $X$. laevis (Ginsberg et al. 1984) proteins, respectively-whereas the RNA polymerase II transcription factor TFIIB is $94 \%$ identical in the two species over its entire length. TFIIIA binds directly to the ICR of type 1 promoters. TFIIIA also binds to 5S RNA to form the 7S storage ribonucleoprotein particle (Pelham and Brown 1980). It is present in massive amounts in immature $X$. laevis oocytes, because they accumulate 5S RNA for later use during oogenesis and the first rounds of embryonic cell division, which occur at a rapid pace in the absence of transcription. This allowed early on the purification of TFIIIA to near homogeneity; indeed, X. laevis TFIIIA was the first eukaryotic transcription factor to be purified (Engelke et al. 1980) and the first for which a corresponding cDNA was isolated (Ginsberg et al. 1984).

Upon binding of $X$. laevis TFIIIA to the $5 S$ gene, the TFIIIA zinc fingers are aligned over the length of the ICR with the C-terminal zinc finger in proximity of the $5^{\prime}$ end, and the N-terminal finger in proximity of the $3^{\prime}$ end, of the ICR (for references, see Paule and White 2000). Zinc fingers 1-3, which contact the $\mathrm{C}$ box, have been reported to contribute most of the binding energy of the entire protein (Clemens et al. 1992; Liao et al. 1992). Interestingly, however, like TFIIIA fragments containing fingers 1-3, fragments containing fingers 4-9 bind, in this case to the A box and intermediate element, with affinities approaching that of the full-length protein (Liao et al. 1992; Kehres et al. 1997). This observation, as well as the binding behavior of full-length proteins with zinc fingers mutated either singly or in pairs, suggest that simultaneous binding by all nine TFIIIA zinc fingers to DNA requires energetically unfavorable distortions, either in the DNA, the protein, or both. Thus, there is negative cooperativity between certain zinc fingers such that loss of binding by a subset of zinc fingers has only a small negative effect on the overall stability of the complex (Kehres et al. 1997). Although TFIIIA on its own is 
displaced from DNA upon passage of RNA polymerase III, the unusual TFIIIA binding properties may contribute to the resilience of the complete $5 \mathrm{~S}$ transcription complex to repeated passage of the RNA polymerase (Bogenhagen et al. 1982; Setzer and Brown 1985; Wolffe et al. 1986; Darby et al. 1988; Kehres et al. 1997).

Surprisingly little is known about how TFIIIA recruits TFIIIC to the DNA. X. laevis TFIIIA contains a 14amino-acid domain located C-terminal of the ninth zinc finger, and thus located toward the $5^{\prime}$ end of the ICR in the TFIIIA/5S gene complex, that is dispensable for DNA binding but essential for transcription (Mao and Darby 1993). In S. cerevisiae TFIIIA, a hydrophobic segment within an 84-amino-acid region located between zinc fingers 8 and 9 is similarly required for cell viability and transcription but not for DNA binding (Rowland and Segall 1998). These protein domains may play a role in the recruitment of TFIIIC.

\section{Recruitment factors: TFIIIC}

The transcription factor TFIIIC is capable of recognizing the TFIIIA-ICR complex on type 1 5S RNA promoters and the variously spaced A and B boxes on type 2 tRNA promoters. The structure of the factor is uniquely adapted to perform these tasks. Proteolysis studies indicate that $S$. cerevisiae TFIIIC consists of two domains separated by a flexible linker, one of which, designated $\tau_{\mathrm{B}}$, binds strongly to the B box and the other, designated $\tau_{\mathrm{A}}$, binds weakly to the A box (Marzouki et al. 1986). Depending on the distance separating the A and B boxes, the factor is visualized by scanning electron microscopy as either two tightly packed or two clearly separated globular domains of roughly similar sizes (Schultz et al.
1989|. These results suggest a factor consisting of two DNA-binding modules separated by a flexible linker that can accommodate variously spaced A and B boxes.

\section{Yeast TFIIIC}

S. cerevisiae TFIIIC consists of six subunits, $\mathrm{Tfc} 3 / \tau 138$,

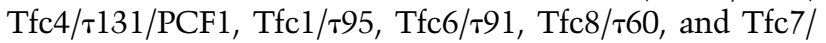
$\tau 55$, all of which have been cloned and shown to be essential for cell viability (Willis et al. 1989; Swanson et al. 1991; Lefebvre et al. 1992; Marck et al. 1993; Arrebola et al. 1998; Manaud et al. 1998; Deprez et al. 1999). Five $S$. pombe proteins have recently been identified by BLAST searches with $S$. cerevisiae TFIIIC subunits as the query, and four of them confirmed as TFIIIC subunits by immunoaffinity purification of a functional TFIIIC complex from cells expressing the tagged polypeptides (Huang et al. 2000). These four subunits, referred to as Sfc1, Sfc3, Sfc4, and Sfc6, are orthologs of S. cerevisiae Tfc1, Tfc3, Tfc4, and Tfc6, respectively, as shown in Table 2. The fifth one, referred to as Sfc9, shares sequence homology with the $S$. cerevisiae Tfc8 subunit within a short C-terminal segment and may, therefore, correspond to the $S$. pombe ortholog of Tfc8. The identification of these $S$. pombe subunits is very interesting because, as detailed below, it clarifies in some cases the relationship between $S$. cerevisiae and human TFIIIC subunits (Huang et al. 2000).

\section{Human TFIIIC}

The human TFIIIC fraction contains several activities, some of which are not yet completely defined. These are

Table 2. Saccharomyces cerevisiae TFIIIC components and orthologues in Schizosaccharomyces pombe and Homo sapiens

\begin{tabular}{|c|c|c|c|}
\hline $\begin{array}{l}\text { S. cerevisiae } \\
\text { TFIIIC }\end{array}$ & $\begin{array}{l}\text { S. pombe } \\
\text { TFIIIC }\end{array}$ & H. sapiens TFIIIC2a & Comments \\
\hline $\mathrm{Tfc} 3 / \tau_{138}$ & Sfc3 & TFIIIC220/TFIIIC $\alpha$ & $\begin{array}{l}\text { Tfc3 and Sfc3 are related, but neither shows sequence similarity to TFIIIC220. } \\
\text { Tfc3 cooperates with Tfc6 for binding to DNA. Fragments of TFIIIC220 and } \\
\text { TFIIIC110 form a subcomplex capable of binding to the B-box. }\end{array}$ \\
\hline $\mathrm{Tfc} 4 / \tau_{131} / \mathrm{PCF} 1$ & Sfc4 & TFIIIC102/TFIIIC $\gamma$ & $\begin{array}{l}\text { Tfc4 protrudes upstream of the start site. TPRs. Tfc } 4 \text { contacts ScBrf1, ScBdp1, } \\
\text { and ABC10 } \alpha \text {. Most conserved of the TFIIIC subunits. TFIIIC102 associates } \\
\text { with HsBrf1, HsTBP, TFIIIC63. }\end{array}$ \\
\hline $\operatorname{Tfc} 1 / \tau_{95}$ & Sfc1 & TFIIIC63/TFIIIC $\varepsilon$ & $\begin{array}{l}\text { tRNA A-box binding. Tfc1 and Tfc7 associate and can form a distinct complex. } \\
\text { TFIIIC63 associates with TFIIIC102, HsBrf1, HsTBP, and HsRPC62. }\end{array}$ \\
\hline $\operatorname{Tfc6}\left(\tau_{91}\right)$ & Sfc6 & TFIIIC110/TFIIIC $\beta$ & $\begin{array}{l}\text { Binds terminator. HMG-I and HMG-Y motifs, WD- } 40 \text { repeats. Similarity } \\
\text { between Tfc6 and TFIIIC110 apparent only through Sfc6. Tfc6 cooperates } \\
\text { with Tfc3 for binding to DNA. TFIIC110 and TFIIIC220 form a subcomplex } \\
\text { capable of binding to the B-box. Full-length TFIIIC110 absent in TFIIIC2b. } \\
\text { TFIIIC110 possesses HAT activity. }\end{array}$ \\
\hline $\operatorname{Tfc} 8\left(\tau_{60}\right)$ & Sfc9 & TFIIIC90/TFIIIC $\delta$ & $\begin{array}{l}\text { Tfc } 8 \text { bridges } \tau_{\mathrm{B}} \text { and } \tau_{\mathrm{A}} \text { domains as well as TFIIIB. Associates with ScTBP. } \\
\text { Similarity of Tfc } 8 \text { and Sf9 limited to short C-terminal segment. No } \\
\text { similarity between TFIIIC90 and the yeast proteins, but TFIIIC90 binds to } \\
\text { TFIIIC220, 110, 63, HsBrf1, HsRPC62, and HsRPC39, and thus may be a } \\
\text { functional homolog of the yeast proteins. TFIIIC90 displays HAT activity for } \\
\text { histone H3 Lys } 14 \text {. }\end{array}$ \\
\hline $\operatorname{Tfc} 7\left(\tau_{55}\right)$ & none & none & tRNA A box binding. Tfc7 and Tfc1 associate and can form distinct complex. \\
\hline
\end{tabular}


summarized in Figure 8. The TFIIIC fraction was originally separated into two fractions, TFIIIC1 and TFIIIC2, that were both required for transcription from the Ad2 VAI gene (Yoshinaga et al. 1987). The TFIIIC1 fraction is only partially defined and is discussed further below. The activity in the TFIIIC2 fraction seems to correspond in part to that of the yeast TFIIIC complex and resides in a complex of five polypeptides referred to as TFIIIC2 or TFIIIC2a (Yoshinaga et al. 1989; Kovelman and Roeder 1992). Human TFIIIC2a has, however, some added activities compared with $S$. cerevisiae TFIIIC (see Table 2). Thus, in cell lines expressing a tagged TFIIIC2a subunit, TFIIIC2a can be purified by immunoprecipitation as part of a larger complex called holo-TFIIIC (see Fig. 8), which is described together with the TFIIIC1 fraction further below (Wang and Roeder 1998; Wang et al. 2000). HoloTFIIIC can bind to chromatin templates, relieves the chromatin-mediated repression of RNA polymerase III transcription from a tRNA gene, and displays histone acetyltransferase (HAT) activity (Kundu et al. 1999), which can be attributed to the intrinsic HAT activity of at least two of the TFIIIC2a subunits (Hsieh et al. 1999a; Kundu et al. 1999).

Besides the active TFIIIC2a complex, the TFIIIC2 fraction contains a transcriptionally inactive TFIIIC2 complex designated TFIIIC2b (Fig. 8; Kovelman and Roeder 1992). TFIIIC2a consists of five subunits referred to as TFIIIC220/TFIIIC $\alpha$, TFIIIC102/TFIIIC $\gamma$, TFIIIC63/TFIIIC $\varepsilon$,
TFIIIC110/TFIIIC $\beta$, and TFIIIC90/TFIIIC $\delta$ /see Table 2), whereas TFIIIC $2 \mathrm{~b}$, which represents $10 \%-20 \%$ of total TFIIIC2 in actively dividing HeLa cells, lacks the TFIIIC110 subunit and appears to contain a $77-\mathrm{kD}$ subunit absent in TFIIIC2a (see Fig. 8; Yoshinaga et al. 1989; Kovelman and Roeder 1992; Sinn et al. 1995). The nature of the $77-\mathrm{kD}$ subunit is not clear; it is not recognized by antibodies generated against the last 595 amino acids of TFIIIC110, suggesting that it either corresponds to an unrelated protein or to a TFIIIC110 fragment devoid of epitopes recognized by the antibody.

The TFIIIC220 subunit functionally corresponds to the $S$. cerevisiae Tfc3 subunit because, like Tfc3, it recognizes the B box (see below; Table 2). Very strikingly, however, it shares no sequence similarity with either $S$. cerevisiae Tfc3 or S. pombe Sfc3p (L'Etoile et al. 1994; Lagna et al. 1994; Huang et al. 2000). Similarly, the human TFIIIC90 protein (Hsieh et al. 1999a) has no obvious sequence homolog in $S$. cerevisiae, but the set of TFIIIC and TFIIIB subunits it interacts with suggest that it is the functional equivalent of Tfc8 (see below). TFIIIC90 has, however, the added property of an intrinsic HAT activity for both free and nucleosomal histone $\mathrm{H} 3$, and preferentially acetylates histone H3 Lys 14 (Hsieh et al. 1999a). The TFIIIC110 subunit corresponds to the yeast Tfc6p protein, although the similarity between the two proteins is apparent only when compared with the $S$. pombe ortholog (Huang et al. 2000). Like TFIIIC90, TFIIIC110

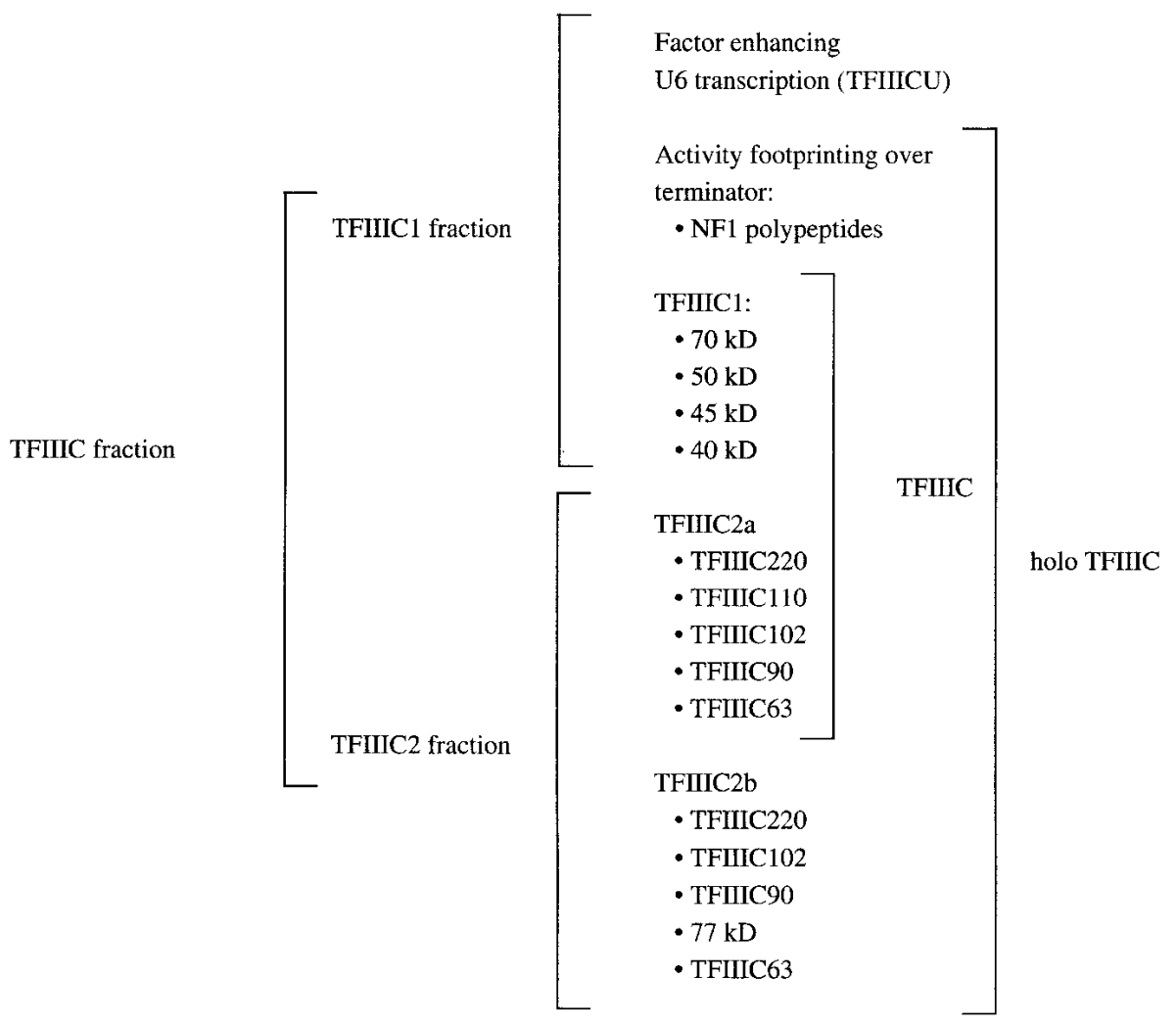

Figure 8. Schematic representing the components identified in the human TFIIIC fraction. Holo-TFIIIC was purified by immunoaffinity from a cell line expressing tagged TFIIIC220 (Wang and Roeder 1998). It is likely, therefore, that it contains TFIIIC2b as well as TFIIIC2a, although this has not been directly demonstrated. See text for references. 
has intrinsic HAT activity, and acetylates free and nucleosomal histones $\mathrm{H} 3$ and $\mathrm{H} 4$ as well as nucleosomal histone H2B (Kundu et al. 1999). In contrast to the human TFIIIC subunits just described, the TFIIIC102 and TFIIIC63 subunits are very clearly related to their yeast counterparts, Tfc4 and Tfcl, respectively (Hsieh et al. 1999b). Thus, human TFIIIC2a is surprisingly divergent from S. cerevisiae TFIIIC in all but two of its subunits. As detailed further below, these two conserved subunits are located close to the transcription start site and interact directly with TFIIIB subunits.

\section{Assembly of a stable initiation complex on type 1 and 2 promoters}

TFIIIC performs at least three functions: It recognizes promoter elements, either directly in the case of type 2 promoters or with the help of TFIIIA in the case of type 1 promoters; it recruits TFIIIB; and it contributes to the recruitment of RNA polymerase III. For all of these functions, we have a good idea of which of the TFIIIC subunits are involved.

\section{Binding of TFIIIC to type 2 and type 1 promoters}

A recombinant complex has not yet been reconstituted either from yeast or human cells, but from both photo- cross-linking (Gabrielsen et al. 1989; Yoshinaga et al. 1989; Bartholomew et al. 1990, 1991; Braun et al. 1992a; Kovelman and Roeder 1992) and protein-protein association experiments (Shen et al. 1996; Manaud et al. 1998; Hsieh et al. 1999a,b), TFIIIC models such as those shown in Figure 9 can be drawn. In Figure 9, the main sites of cross-linking between yeast subunits and DNA are indicated with dots. Known protein-protein contacts among TFIIIC subunits are indicated by dashes according to whether they were demonstrated with human (black) or yeast (gray) subunits.

On the SUP4 tRNA gene, the $S$. cerevisiae Tfc3 subunit cross-links primarily just upstream of the B box and Tfc6 cross-links at the end of the gene (Bartholomew et al. 1990, 1991). The two proteins probably cooperate to bind to DNA because a mutation in Tfc6 can alleviate the binding defect of a Tfc3 mutant (Arrebola et al. 1998). Consistent with Tfc3 and Tfc6 corresponding to human TFIIIC220 and TFIIIC110, respectively, human TFIIIC220 can be cross-linked to the B box (Yoshinaga et al. 1989; Kovelman and Roeder 1992). Moreover, TFIIIC220 does not bind DNA on its own, but it is part of TFIIIC subassemblies generated by proteinase $C$ cleavage during poliovirus infection that are still capable of binding to DNA (Clark et al. 1991). Some of these subcomplexes consist of just the N-terminal $83 \mathrm{kD}$ of TFIIIC220 associated with the TFIIIC110 subunit or a
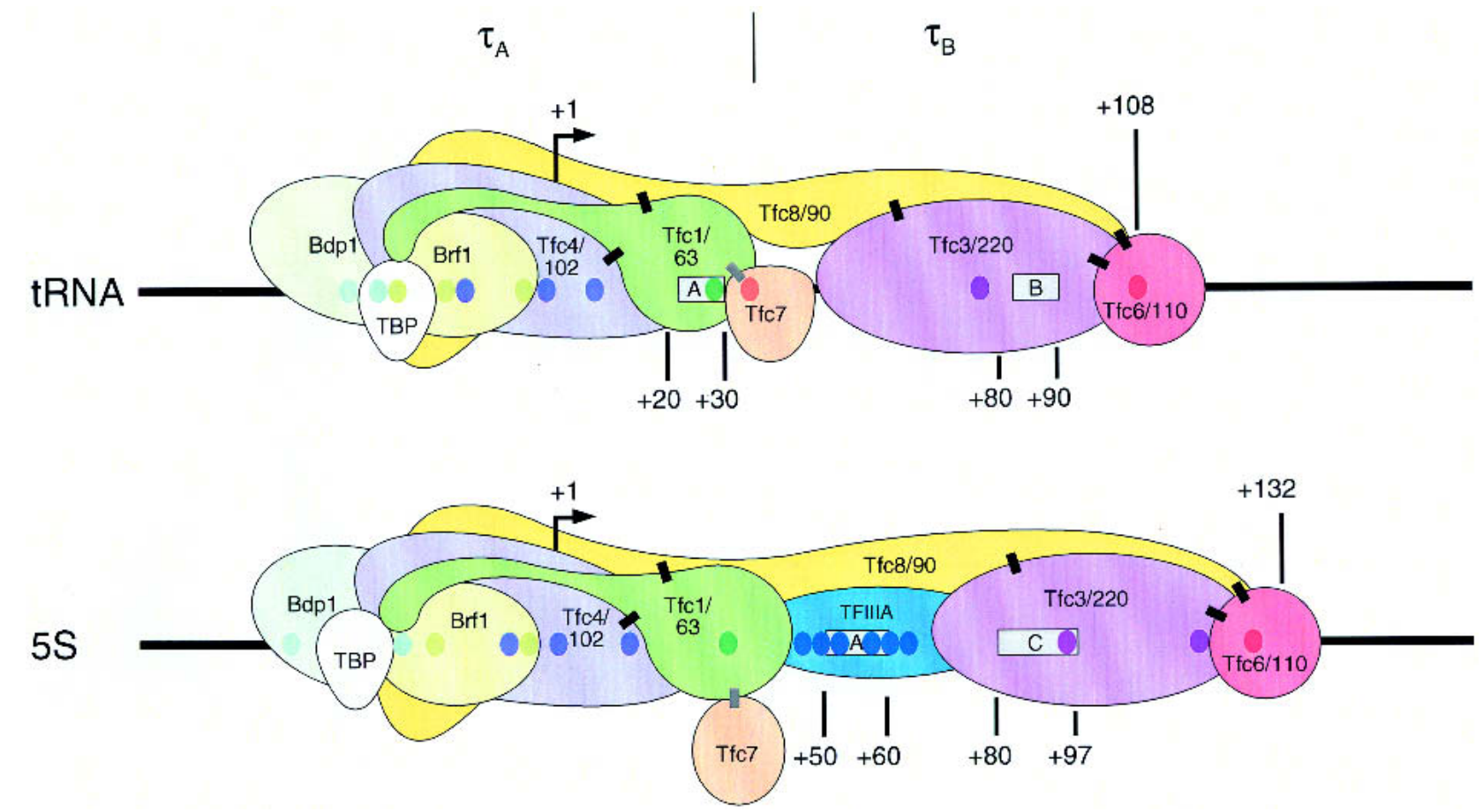

Figure 9. The position of the various Sc TFIIIC and TFIIIB subunits on an SUP4 tRNA and 5S gene as determined by cross-linking and protein-protein association experiments (see text) are indicated. For the TFIIIC subunits, the names of both the Saccharomyces cerevisiae and the human subunits are indicated. The positions of the start site, end of the gene, and A, B, and C boxes are indicated. A bend in the DNA at the TFIIIB binding site is not illustrated in the figure. The colored dots indicate major cross-linking sites of the subunit of matching color to the DNA. The Tfc8 subunit is shown as an elongated shape extending over most of the TFIIIC complex because it appears to bridge the TFIIIC $\tau_{\mathrm{A}}$ and $\tau_{\mathrm{B}}$ domains as well as TFIIIB. The black and gray rectangles illustrate protein-protein contacts identified with human and $S$. cerevisiae TFIIIC subunits, respectively. Protein-protein contacts between TFIIIC and TFIIIB subunits are summarized in Figure 10A. 
fragment thereof, indicating that the DNA-binding domain of TFIIIC220 lies within the $\mathrm{N}$-terminal region of the protein and that TFIIIC220 and TFIIIC110 are sufficient to generate the DNA-binding surface of the TFIIIC2a complex (Shen et al. 1996). Note that an essential role for the TFIIIC110 subunit in DNA binding implies that the TFIIIC2b complex, which can bind DNA specifically, contains either an unrecognized TFIIIC110 fragment or another protein (e.g., the $77-\mathrm{kD}$ protein) providing the TFIIIC110 DNA-binding function.

The yeast Tfcl and Tfc7 subunits have strong crosslinks within and near the $3^{\prime}$ end of the A box, respectively (Bartholomew et al. 1990, 1991). Tfc7 interacts directly with Tfcl through its C-terminal half, and the two proteins are not only part of TFIIIC but also form a separate complex in yeast cells (Manaud et al. 1998). Tfc8 does not cross-link to DNA. When TFIIIC is treated with protease, Tfc 8 is found in the $\tau_{\mathrm{B}}$ domain as determined by antibody supershift experiments. In addition, however, the temperature sensitivity observed with strains expressing an epitope tagged version of Tfc 8 is specifically suppressed by overexpression of Tfc1, which resides in the $\tau_{\mathrm{A}}$ domain. It is also suppressed by overexpression of TBP and ScBdp1, and Tfc 8 associates with TBP in vitro (Deprez et al. 1999). Human TFIIIC90 is thought to be the functional homolog of Tfc8 because it interacts with TFIIIC220, TFIIIC110, and TFIIIC63, as well as with the TFIIIB subunit HsBrfl (Hsieh et al. 1999a). Thus Tfc8/TFIIIC90 appears to bridge the TFIIIC $\tau_{\mathrm{B}}$ and $\tau_{\mathrm{A}}$ domains as well as TFIIIB, and is represented, therefore, as extending over the entire gene in Figure 9. The Tfc4 subunit cross-links to sites around and upstream of the transcription start site (Bartholomew et al. 1990, 1991) and directly contacts both the ScBrf1 and ScBdp1 subunits of TFIIIB (Khoo et al. 1994; Chaussivert et al. 1995; Rüth et al. 1996; Dumay-Odelot et al. 2002). Its location on the DNA is consistent with the human ortholog, TFIIIC102, interacting with TFIIIC63, TBP, and HsBrf1 (Hsieh et al. 1999b). Tfc1/TFIIIC63 is shown extending upstream of the transcription start site because the human subunit, like TFIIIC102, contacts HsBrf1 and TBP (Hsieh et al. 1999b).

On the 5S RNA genes, S. cerevisiae TFIIIA cross-links strongly to the A box and much more weakly to positions as far upstream as +20 and as far downstream as +127 , and thus extends over a large portion of the gene (only the cross-links on the A box are shown in Fig. 9; Braun et al. 1992a). TF3C appears shifted downstream as compared with its position in the tRNA gene, with a main cross-link at the $3^{\prime}$ end of the $\mathrm{C}$ box and another one further downstream. As in the tRNA gene, the Tfc6 subunit cross-links at the end of the gene. There is no indication that the Tfc7 subunit contacts DNA in the 5S gene, but the Tfcl subunit cross-links strongly upstream of the A box. Thus, the 5S A box is clearly not the functional equivalent of the tRNA A box. Rather, the functional equivalent of the tRNA A box in the $5 S$ gene is the site of Tfcl cross-linking, which in both genes occurs about $30 \mathrm{nt}$ downstream of the transcription start site. As in the SUP4 tRNA gene, the Tfc4 subunit cross-links to sites around and upstream of the start site of transcription (Braun et al. 1992a).

\section{TFIIIC recruitment of TFIIIB}

The role of TFIIIC in the recruitment of TFIIIB has been intensively studied in $S$. cerevisiae. Experiments in which various TFIIIB components were added sequentially to a TFIIIC-DNA complex suggest that the TFIIICDNA complex interacts initially with the Brf1 component of TFIIIB (Kassavetis et al. 1992), most probably through the Tfc4 subunit, which protrudes upstream of the transcription start site (see Fig. 9). Like the interaction of TFIIIC with its bipartite binding site on DNA, the interaction of TFIIIC with TFIIIB is highly flexible. Thus, when TFIIIB is recruited by TFIIIC on SUP4 tRNA ${ }^{\text {Tyr }}$ gene constructs with TATA boxes inserted at various positions upstream of the A box and TFIIIC is subsequently stripped from the DNA by heparin treatment, the upstream and downstream borders of the footprint occasioned by the remaining TFIIIB vary according to the position of the TATA box. On the same constructs, the footprint of TFIIIC alone is invariant, but the footprint attributable to TFIIIC (heparin-sensitive) in the presence of TFIIIB extends to cover the interval between the borders of the variant TFIIIB footprint and that of the invariant TFIIIC footprint observed with TFIIIC alone. Thus, the placement of TFIIIB is codirected by the TATA box (and thus probably the TBP subunit of TFIIIB) and TFIIIC. Furthermore, because the interval protected is the region to which the Tfc4 subunit of TFIIIC crosslinks, these results suggest that $\mathrm{Tfc} 4$ can extend to accommodate various spacings between TFIIIB and TFIIIC (Joazeiro et al. 1996).

Tfc4 contains 11 copies of the tetratricopeptide repeat (TPR) in four blocks of 5, 4, 1, and 1 repeats (Marck et al. 1993; Rameau et al. 1994; Dumay-Odelot et al. 2002). TPRs are found in a large number of proteins including subunits of the anaphase-promoting complex and the transcription repressor Ssn6. The crystal structures of several TPR domains indicate that each TPR consists of a pair of antiparallel $\alpha$-helices, and that adjacent TPRs are packed in regular series of antiparallel $\alpha$-helices (Das et al. 1998; Scheufler et al. 2000). Truncated Tfc4 proteins encompassing the $\mathrm{N}$-terminal, middle, and C-terminal third of the protein including the first (repeats 1-5), second (repeats 6-9), and last (repeats 10 and 11) blocks of TPRs, respectively, all bind to ScBrf1 in a GST pull-down assay (Khoo et al. 1994). Quantitative in vitro equilibrium binding assays with various truncated forms of Tfc4 also detect several fragments capable of binding to ScBrf1, of which the two with the highest affinities extend from the $\mathrm{N}$ terminus of the protein to the end of repeat 5, and from repeat 6 to repeat 9 (Moir et al. 2002a). Interestingly, both fragments have higher affinities for ScBrf1 than a larger fragment extending from the $\mathrm{N}$ terminus to repeat 9 (Moir et al. 2002a), consistent with the observation that in a yeast two-hybrid assay, a similar long Tfc4 fragment shows weaker association than frag- 
ments shorter at the $\mathrm{C}$ terminus (Chaussivert et al. 1995). These results suggest that there is autoinhibition for ScBrf1 binding within Tfc4, which is probably relieved by conformational changes during binding.

Conformational changes within Tfc4 are also suggested by an analysis of two dominant Tfc4 mutations, $P C F-1$ and PCF-2, that map within repeats $1-3$. These mutations increase transcription both in vivo and in vitro by increasing the recruitment of TFIIIB, specifically the binding of Tfc4 to ScBrf1 (Rameau et al. 1994; Moir et al. 1997, 2002b). For PCF1-1, biochemical studies indicate that this effect is achieved via a conformational change in Tfc4 that overcomes autoinhibition in the ScBrf1 binding reaction (Moir et al. 2000, 2002a,b). Thus, the TPRs appear to be involved in conformational changes that promote association with ScBrf1 and accommodate the variable placement of TFIIIB. The positive effect of the mutations indicates that the recruitment of TFIIIB is a limiting step in vivo, and that the conformational change may therefore serve a regulatory role.

Other associations have been observed between isolated TFIIIC and TFIIIB subunits. These are symbolized in Figure 10A with arrows, according to whether the association was demonstrated with human (solid) or yeast (hatched) TFIIIC subunits. As just described, Tfc4 associates with ScBrf1, and it also associates with ScBdp1 (Khoo et al. 1994; Chaussivert et al. 1995; Rüth et al. 1996; Dumay-Odelot et al. 2002). The human ortholog TFIIIC102 associates with both HsBrf1 and HsTBP
(Hsieh et al. 1999b). Tfc8 associates with ScBdpl and ScTBP (Deprez et al. 1999), and the human ortholog TFIIIC90 with HsBrf1 (Hsieh et al. 1999a). TFIIIC63 associates with both HsBrf1 and HsTBP (Hsieh et al. $1999 \mathrm{~b})$. Thus, there is a network of protein-protein contacts between TFIIIC and TFIIIB, all of which may participate in the recruitment of TFIIIB during transcription initiation.

\section{TFIIIC contacts RNA polymerase III}

Several of the TFIIIC subunits have been shown to interact directly with RNA polymerase III subunits, and these interactions are depicted in Figure 10B with solid arrows for associations demonstrated with human subunits and hatched arrows for associations demonstrated with $S$. cerevisiae subunits. The Tfc4 TFIIIC subunit interacts with the RNA polymerase III C53 subunit in a two-hybrid assay (Flores et al. 1999), and with the conserved C-terminal domain of the universal RNA polymerase subunit $\mathrm{ABC} 10 \alpha$ in both a yeast two-hybrid assay and in vitro. This latter interaction is likely to be functionally significant because a thermosensitive mutation within the $\mathrm{C}$-terminal domain of $\mathrm{ABC} 10 \alpha$ that weakens the interaction can be rescued in an allele-specific manner by overexpression of a variant form of $\mathrm{Tfc} 4$ that strengthens the interaction (Dumay et al. 1999). Among the human TFIIIC subunits, the TFIIIC90 protein interacts with HsRPC62 and HsRPC39, which are both part of the subcomplex of RNA polymerase III subunits re-
Figure 10. Protein-protein contacts between TFIIIC and TFIIIB subunits, and TFIIIC and RNA polymerase III subunits. Contacts as determined either by in vitro or yeast two-hybrid assays are depicted. Genetic interactions have not been included. Solid arrows depict interactions shown with human proteins, stippled arrows depict interactions shown with Saccharomyces cerevisiae proteins. See text for references. (A) Protein-protein contacts between TFIIIC and TFIIIB subunits. (B) Protein-protein contacts between TFIIIC and RNA polymerase III subunits.

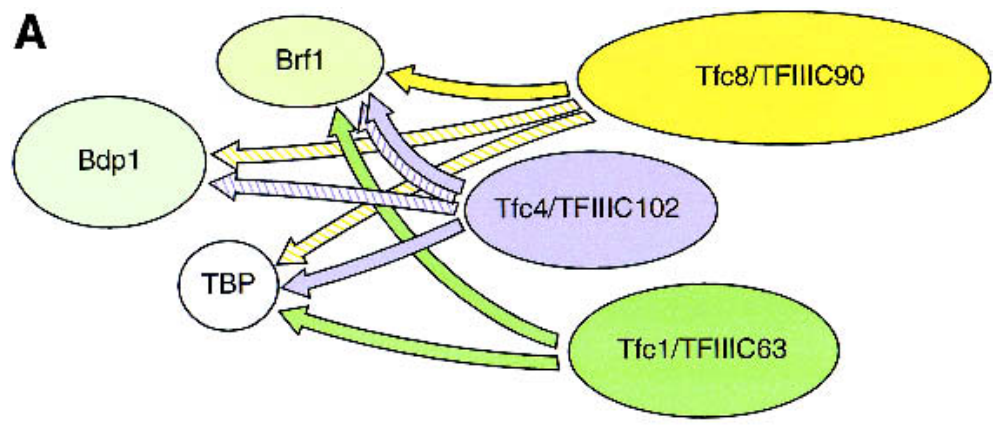

B

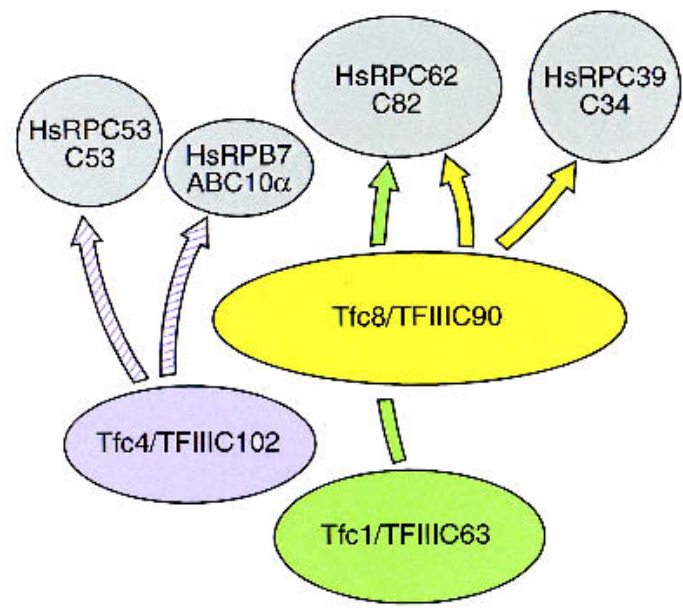


quired specifically for transcription initiation, and TFIIIC63 associates with HsRPC62 in vitro (Hsieh et al. 1999a). These TFIIIC-RNA polymerase III interactions emphasize that TFIIIC not only recruits TFIIIB but may also participate in the recruitment of RNA polymerase III. Thus, although TFIIIB is sufficient to recruit RNA polymerase III, in the cell both TFIIIB and TFIIIC are likely to work in concert to recruit the RNA polymerase.

\section{Recruitment factors: SNAP $_{c}$}

Type 3 promoters do not contain binding sites for TFIIIA and/or TFIIIC2, and, indeed, they do not require TFIIIC2 for assembly of a transcription initiation complex. Thus, depletion of a transcription extract with antibodies directed against the DNA-binding subunit of TFIIIC2, TFIIIC220, affects transcription from the 5S, tRNA, and VAI genes but not from the 7SK and U6 snRNA genes (Lagna et al. 1994). Instead, the gene-external PSE of type 3 promoters recruits the multisubunit complex $\mathrm{SNAP}_{\mathrm{c}}$. $\mathrm{SNAP}_{\mathrm{c}}$ is a complex containing five different subunits, SNAP190 (Wong et al. 1998), SNAP50/PTFß (Bai et al. 1996; Henry et al. 1996), SNAP45/PTFס (Sadowski et al. 1996; Yoon and Roeder 1996), SNAP43/PTFy (Henry et al. 1995; Yoon and Roeder 1996), and SNAP19 (Henry et al. 1998b). In the human system, $\mathrm{SNAP}_{\mathrm{c}}$ is involved in transcription of snRNA genes by both RNA polymerases II and III, as depletion of endogenous $\mathrm{SNAP}_{\mathrm{c}}$ from transcription extracts debilitates U1 and U6 transcription and transcription can be restored in both cases by addition of highly purified recombinant $\operatorname{SNAP}_{\mathrm{c}}$ (Henry et al. 1998b).

The subunit-subunit contacts within $\operatorname{SNAP}_{c}$ have been determined by reconstitution of partial complexes and coimmunoprecipitations of various subsets of in vitro translated full-length or truncated $\mathrm{SNAP}_{\mathrm{c}}$ subunits (Henry et al. 1996, 1998a,b; Wong et al. 1998; Mittal et al. 1999; Ma and Hernandez 2000, 2002). Figure 11A shows the general architecture of the complex. SNAP19 and SNAP45 can each associate independently with SNAP190, and SNAP43 can associate independently with SNAP50. SNAP43 can also associate with SNAP190, but in coimmunoprecipitations of in vitro translated proteins, this association is not detectable unless SNAP19 is present. This suggests that SNAP43 has weak contacts with both SNAP190 and SNAP19, only the sum of which is measurable by the stringent coimmunoprecipitation assay (Henry et al. 1998b). However, partial complexes containing SNAP190 or a truncated SNAP190, SNAP43, and SNAP50 can be assembled both in insect cells infected with recombinant baculoviruses (Mittal et al. 1999) and from subunits overexpressed in E. coli (Ma and Hernandez 2000, 2002), indicating that in these situations SNAP19 is dispensable for complex assembly.

The domains involved in protein-protein contacts are summarized in Figure 11B. Within SNAP190, amino acids 84-133 are sufficient for association with SNAP19 alone, and with SNAP43 together with SNAP19. This SNAP190 region, and the N-terminal part of SNAP19, are likely to form $\alpha$-helices and may be involved in a coiled-coil type of interaction with each other. In SNAP43, amino acids 164-268 are sufficient for association with SNAP190 together with SNAP19, and amino acids 1-163 are sufficient for association with SNAP50. Thus, these two association domains in SNAP43 are completely separable. The SNAP190 region required for interaction with SNAP45 lies between amino acids 1281 and 1393. The SNAP190 regions required for association with SNAP19/SNAP43 and with SNAP45 thus lie at opposite ends of the linear molecule ( $\mathrm{Ma}$ and Hernandez 2000).

SNAP $_{c}$ binds specifically to the PSE. This binding is mediated in part by an unusual Myb domain extending from amino acids 263 to 503 within SNAP190, with four and one-half Myb repeats designated the $\mathrm{Rh}(\underline{\mathrm{R}} \underline{\mathrm{h}}$ alf), $\mathrm{Ra}$, $\mathrm{Rb}, \mathrm{Rc}$, and Rd repeats (see Fig. 11B; Wong et al. 1998). Indeed, a SNAP190 segment consisting of just the Myb domain can bind to the PSE (Wong et al. 1998), and in the
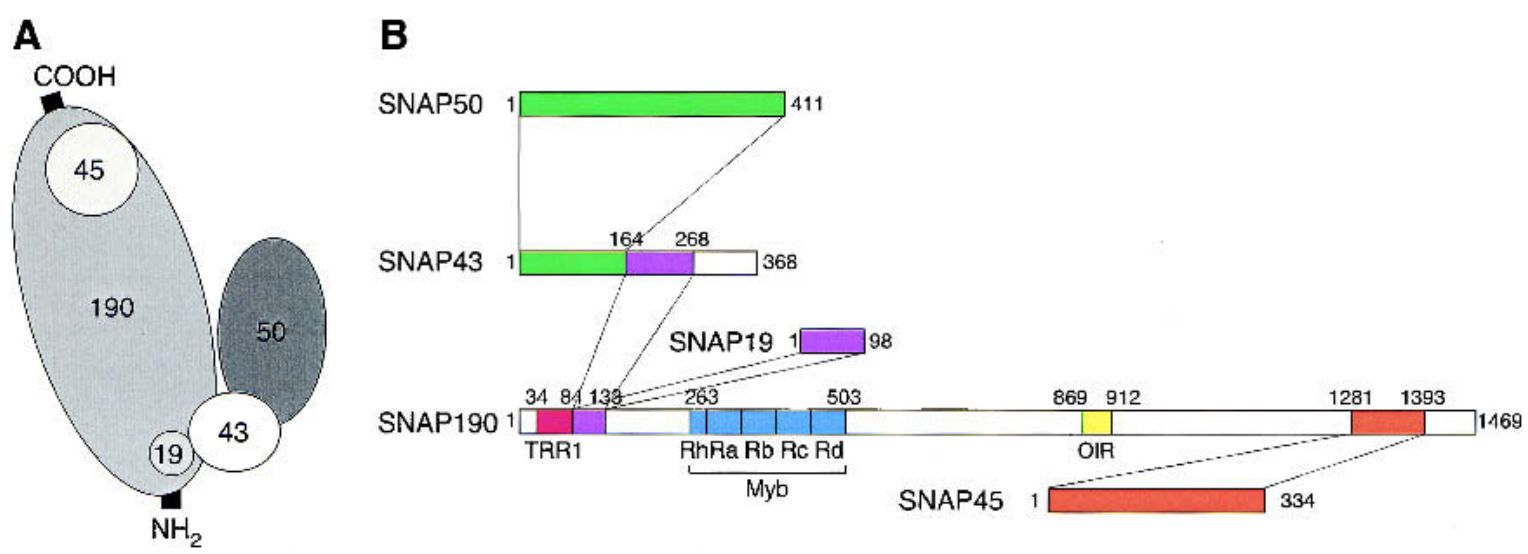

Figure 11. Subunit-subunit interactions within $\operatorname{SNAP}_{\mathrm{c}} \cdot(A)$ For simplicity, the complex is shown as containing one copy of each subunit, but the stoichiometry of the $\operatorname{SNAP}_{\mathrm{c}}$ subunits has not been determined. $(B)$ The domains of the various subunits sufficient for association with other subunits in a coimmunoprecipitation assay. The TBP recruitment region 1 (TRR1), the Myb domain with the half repeat $(\mathrm{Rh})$ followed by four repeats $(\mathrm{Ra}, \mathrm{Rb}, \mathrm{Rc}$, and $\mathrm{Rd})$, and the Oct-1 interacting region (OIR) are shown. 
context of the full complex, the last two Myb repeats (Rc and $\mathrm{Rd})$, but not the first two and one-half (Rh, $\mathrm{Ra}$, and $\mathrm{Rb}$ ), are required for binding to the PSE (Mittal et al. 1999). However, even though the Myb domain is required, it is not sufficient. Thus, although a SNAP190 segment consisting of just the Myb domain binds DNA, larger SNAP190 segments do not. The smallest subassembly of $\mathrm{SNAP}_{\mathrm{c}}$ subunits characterized that binds specifically to DNA consists of SNAP190 amino acids 84505, SNAP43 amino acids 1-268, and SNAP50 (complex \#8; Ma and Hernandez 2000, 2002). Consistent with the requirement for parts of SNAP190 and SNAP50 for DNA binding, UV cross-linking experiments suggest that both SNAP190 (Yoon et al. 1995) and SNAP50 (Henry et al. 1996) are in close contact with DNA.

\section{Assembly of a stable transcription complex on the type 3 U6 snRNA promoter}

As noted above, the type 3 promoters such as the U6 promoter contain, in addition to core sequences, a DSE that serves to enhance transcription from the core promoter (see Fig. 1). The DSE can contain a number of protein-binding sites, but two of them are almost invariably an SPH (also called NONOCT) element, which recruits the transcription factor STAF (also called SPHbinding factor or SBF), and an octamer sequence, which recruits the transcription factor Oct-1 (for reviews, see Hernandez 1992, 2001).

STAF is a zinc finger protein, and Oct- 1 is a founding member of the POU-domain protein family. Both proteins contain two types of activation domains, one type that specifically activates mRNA-type RNA polymerase II promoters and another that specifically activates both type 3 RNA polymerase III promoters and the very similar RNA polymerase II snRNA promoters (Tanaka et al. 1992; Das et al. 1995; Schuster et al. 1998). The presence of the latter type of activation domains in STAF and Oct-1 supports the idea that these proteins activate type 3 promoters (as well as RNA polymerase II snRNA promoters) in the cell. Indeed, both proteins have been localized to snRNA promoter sequences in vivo by chromatin immunoprecipitation experiments (Zhao et al. 2001; Mach et al. 2002). Thus, as for the core promoter sequences of type 3 promoters, the key factors recruited by the DSE are well characterized and are available in recombinant form.

The identification of the factors binding directly to type 3 promoter elements has allowed the characterization of their assembly onto a human U6 promoter. Our present understanding of this process is summarized in Figure 12 . SNAP $_{c}$ binds poorly to DNA on its own. Interestingly, however, a partial complex lacking the Cterminal two-thirds of the largest subunit of $\mathrm{SNAP}_{\mathrm{c}}$ as well as SNAP45, referred to as mini-SNAP ${ }_{c}$, binds more efficiently to the DNA (Mittal et al. 1999). This implies that the C-terminal two-thirds of SNAP190 and/or SNAP45, which associates with the C-terminal portion of SNAP190, somehow down-regulate binding of the complex to DNA. On the U6 promoter, however, $\mathrm{SNAP}_{\mathrm{c}}$

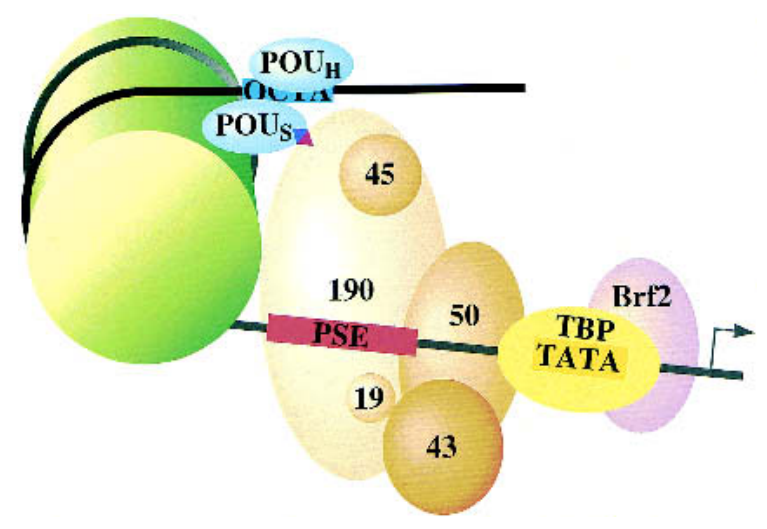

Figure 12. Human U6 transcription initiation complex. TBP (yellow) and $\mathrm{SNAP}_{\mathrm{c}}$ (orange) bind cooperatively to the DNA, presumably through a direct protein-protein contact that involves a 50 -amino-acid segment within the $\mathrm{N}$-terminal region of SNAP190. TBP also binds cooperatively with Brf2. SNAP and the Oct-1 POU domain (blue) bind cooperatively to DNA, through a direct protein-protein contact involving a glutamic acid at position 7 within the $\mathrm{POU}_{\mathrm{S}}$ domain (blue triangle) and a lysine at position 900 within SNAP190 (red triangle). This direct protein-protein interaction is mediated by a positioned nucleosome (green) that brings into close proximity the octamer sequence and the PSE. Adapted from Zhao et al. (2001). See text for references.

is efficiently recruited to the DNA through at least two cooperative binding interactions. $\mathrm{SNAP}_{\mathrm{c}}$ binds cooperatively with TBP, which like $\mathrm{SNAP}_{\mathrm{c}}$ binds poorly to DNA on its own, and with the Oct-1 POU domain (Murphy et al. 1992; Mittal et al. 1996; Mittal and Hernandez 1997).

In cooperative binding of $\mathrm{SNAP}_{\mathrm{c}}$ and TBP, both factors recruit each other to the DNA. Mini-SNAP ${ }_{c}$ is also able to bind cooperatively with TBP, although in this case, cooperative binding results mainly in the recruitment of TBP, because mini-SNAP ${ }_{c}$ binds efficiently to DNA on its own (Mittal et al. 1999). Within the context of mini$\mathrm{SNAP}_{\mathrm{c}}$ a 50-amino-acid segment within the $\mathrm{N}$-terminal region of SNAP190, called TRR1 (TBP recruitment region $\underline{1}$; see Fig. 11) is required for cooperative binding with TBP. Interestingly, mini-SNAP ${ }_{\mathrm{c}}$ complexes lacking these 50 amino acids are active for transcription, suggesting that during assembly of the U6 transcription initiation complex, there are redundant mechanisms to recruit TBP to the DNA. Indeed, TBP is efficiently recruited to the DNA by cooperative binding with HsBrf2 to form a complex containing mini-SNAP ${ }_{c}, \mathrm{TBP}_{\text {, and }}$ HsBrf2 (Ma and Hernandez 2002), and TBP is therefore shown contacting both $\mathrm{SNAP}_{\mathrm{c}}$ and HsBrf2 in Figure 12. It remains possible that in the absence of the DSE, cooperative binding of TBP and $\mathrm{SNAP}_{c}$ is essential to recruit the full $\mathrm{SNAP}_{\mathrm{c}}$ to the DNA, which, unlike miniSNAP $_{c}$, binds poorly to the PSE. In the presence of the DSE, however, the full SNAP can be recruited to the DNA by the Oct-1 POU domain.

The Oct-1 POU domain is a bipartite DNA-binding domain consisting of two helix-turn-helix-containing DNA-binding modules: an N-terminal POU-specific 
$\left(\mathrm{POU}_{\mathrm{S}}\right)$ domain and a C-terminal POU-homeo domain $\left(\mathrm{POU}_{\mathrm{H}}\right)$, joined by a flexible linker (Herr and Cleary 1995). The POU domains of Oct-1 and the pituitary transcription factor Pit-1 are $\sim 50 \%$ identical, but only the Oct-1 POU domain is capable of recruiting SNAP $_{c}$ to the PSE. This difference in activity is due to only one of the many amino acid differences between the two proteins, a glutamic acid at position 7 in the Oct-1 $\mathrm{POU}_{\mathrm{S}}$ domain changed to an arginine at the corresponding position in the Pit-1 POU $\mathrm{PO}_{\mathrm{S}}$ domain. Thus, an E7R mutation in Oct-1 does not affect Oct-1 binding to the octamer sequence but inhibits cooperative binding with $\mathrm{SNAP}_{\mathrm{c}}$, and an R7E mutation in Pit-1 imparts to this protein the ability to bind cooperatively with $\operatorname{SNAP}_{\mathrm{c}}$ (Mittal et al. 1996).

Oct-1 associates with SNAP190, the largest subunit of $\mathrm{SNAP}_{\mathrm{c}}$, both in a yeast one-hybrid assay and in an electrophoretic mobility shift assay (Ford et al. 1998; Wong et al. 1998). This suggested that cooperative binding of the Oct-1 POU domain and $\mathrm{SNAP}_{\mathrm{c}}$ may result from a protein-protein contact between the POU domain and SNAP190. Indeed, a small domain of SNAP190 extending from amino acids 869 to 912 and labeled OIR (O-ct1 -interacting region) in Figure 11 above is sufficient for association with the Oct-1 POU domain in an electrophoretic mobility shift assay. Strikingly, the OIR of SNAP190 displays sequence similarity with the Oct-1 POU-domain-interacting region present in OBF-1/ OCA-B (Ford et al. 1998). OBF-1 is a B-cell-specific coactivator of Oct-1, which recognizes Oct-1 bound to an octamer sequence and provides a strong activation domain of mRNA gene transcription. As with SNAP190, the association of OBF-1 with the Oct-1 POU domain is sensitive to the E7R mutation in Oct-1 (Babb et al. 1997), and, indeed, the Oct-1 POU E7 is involved in a hydrogen bond with a lysine in OCA-B as shown in the crystal structure of an OCA-B peptide associated with an Oct-1 POU/octamer sequence complex (Chasman et al. 1999). Thus, two proteins with different tissue distribution, function, and primary structure nevertheless share a common Oct-1 binding domain, and probably contact overlapping surfaces in the Oct-1 POU domain (Ford et al. 1998).

Within the SNAP190 OIR, mutation of Lys 900 to a glutamic acid (K900E mutation) inhibits cooperative binding of $\mathrm{SNAP}_{\mathrm{c}}$ with the Oct-1 POU domain. Very significantly, however, if $\mathrm{SNAP}_{\mathrm{c}}$ carrying the K900E mutation within SNAP190 is combined with the Oct-1 POU domain carrying the E7R mutation, significant cooperative binding is restored (Ford et al. 1998). The isolation of these paired altered specificity mutants indicates that cooperative binding requires a direct proteinprotein contact, and suggests that this contact involves K900 in SNAP190 and E7 in the Oct-1 POU domain. K900 (Fig. 12, red triangle) and E7 (Fig. 12, blue triangle) are, therefore, shown contacting each other in Figure 12. In $\mathrm{SNAP}_{c}$, then, the same region of the complex that is required for down-regulation of DNA binding is involved in a protein-protein interaction that mediates cooperative binding such that, in effect, cooperative binding inactivates a $\mathrm{SNAP}_{\mathrm{c}}$ built-in damper of DNA binding.
The recruitment of $\mathrm{SNAP}_{\mathrm{c}}$ by the Oct-1 POU domain contributes to transcription activation in vitro. Therefore, Oct-1 is likely to activate snRNA gene transcription in vivo not only through its transcription activation domains but also through its DNA-binding domain. This activation can be compared to activation in prokaryotes by the $\lambda$ cI repressor, which activates transcription from the $\lambda P_{\mathrm{RM}}$ promoter by favoring open complex formation through direct protein-protein contacts between its DNA-binding domain and RNA polymerase (for references, see Ford et al. 1998). Strikingly, the DNA-binding domain of the $\lambda \mathrm{cI}$ repressor is structurally similar to the Oct-1 POU $\mathrm{PO}_{\mathrm{S}}$ domain, and the RNA polymerase subunit contacted by the cI DNA-binding domain is the $\sigma$ subunit, which is, like $\mathrm{SNAP}_{\mathrm{c}}$, a core promoter binding factor. This illustrates how E. coli and human cells can use similar protein-protein contacts to activate transcription.

The Oct-1-SNAP interaction was originally characterized with U6 promoter probes in which the octamer sequence had been placed close to the PSE. The exact distance separating the octamer and the PSE was not important, but not surprisingly, cooperative binding was not observed on the natural promoter, where the two sites are separated by $\sim 150 \mathrm{bp}$. This suggested that in the natural U6 promoter the two sites may somehow be brought into close proximity for cooperative binding. Indeed, as shown in Figure 12, the human U6 promoter harbors a positioned nucleosome between the octamer sequence and the PSE, both in vivo as determined by micrococcal nuclease sensitivity of the chromatin and in vitro upon assembly of a U6 template into nucleosomes (Stunkel et al. 1997; Zhao et al. 2001). The positioned nucleosome promotes activation by the Oct-1 POU domain from its natural binding site as well as cooperative binding of Oct-1 and $\mathrm{SNAP}_{\mathrm{c}}$. This cooperative binding is affected by the Oct-1 E7R and the SNAP190 K900E mutations, but is restored to significant levels when the two mutant factors are combined (Zhao et al. 2001). Thus, the positioned nucleosome mediates a direct proteinprotein contact between the Oct-1 POU domain and SNAP $_{c}$, and this contact is the same as the one characterized on probes containing closely spaced octamer and PSE. This provides a striking example of a nucleosome, the structural unit of chromatin, activating transcription by serving an architectural role and thus allowing cooperative interactions of factors binding to distant sites.

The assembly of the U6 transcription complex illustrates how a network of cooperative interactions ultimately increases both the affinity and the DNA-binding specificity of factors such as $\mathrm{SNAP}_{\mathrm{c}}$ and TBP which, on their own, display slow on and off rates and relatively low DNA-binding specificity. Both $\mathrm{SNAP}_{\mathrm{c}}$ and TBP contain built-in dampers of DNA binding. In the case of $\mathrm{SNAP}_{\mathrm{c}}$, the damper is deactivated by cooperative interactions with Oct-1, which dramatically enhance the $\mathrm{SNAP}_{\mathrm{c}}$ on rate (Mittal et al. 1996). In the case of TBP, the damper is deactivated by cooperative interactions with SNAP $_{c}$ (Mittal and Hernandez 1997). Because cooperative interactions between Oct-1 and $\mathrm{SNAP}_{\mathrm{c}}$, and $\mathrm{SNAP}_{\mathrm{c}}$ 
and TBP, only take place when the corresponding DNAbinding sites are all present, such interactions limit, in effect, the binding of these factors to promoter sequences.

\section{Stepwise assembly versus holoenzyme}

Our understanding of how RNA polymerase III is recruited to specific promoters stems from in vitro studies in which transcription initiation complexes are assembled by stepwise addition of various components. Such studies have brought invaluable information about the network of protein-DNA and protein-protein interactions that culminates in the specific recruitment of RNA polymerase III. In vivo, however, it is possible that many of the factors that mediate promoter recognition by RNA polymerase III are recruited together with the polymerase as part of a holoenzyme. Indeed, anti-epitope tag immunoprecipitates from a human cell line stably synthesizing a tagged subunit of RNA polymerase III can direct transcription from type 2 promoters on their own and from type 1 promoters when combined with TFIIIA (Wang et al. 1997). Consistent with this observation, these immunoprecipitates contain the TFIIIB subunits TBP and HsBrf1 as well as the TFIIIC2 subunits TFIIIC220 and TFIIIC110 as determined by immunoblot. Tandem immunoprecipitations as well as gel filtration analyses indicate that about $10 \%$ of the RNA polymerase molecules in the immunoprecipitate is associated with TFIIIB and/or TFIIIC components. However, these associations are reduced by an increase in the $\mathrm{KCl}$ concentration from $100 \mathrm{mM}$ to $150 \mathrm{mM}$, and are lost at 300 $\mathrm{mM} \mathrm{KCl}$. Nevertheless, these results raise the possibility that in vivo, RNA polymerase III is recruited together with some of its accessory factors, in particular TFIIIB and TFIIIC2 (Wang et al. 1997).

\section{Human TFIIIC1}

The human TFIIIC fraction contains the B-box-binding TFIIIIC2 complex described above as well as the TFIIIC1 activity, which displays no strong DNA-binding activity on its own but extends the TFIIIC2 footprint both upstream on the A box and downstream to the end of the gene (Yoshinaga et al. 1987). TFIIIC1 is apparently required not only for transcription from type 1 and 2 promoters, but also for transcription from the type 3 geneexternal promoters (Yoon et al. 1995). As summarized in Figure 8 , this fraction contains a number of factors that have been implicated in RNA polymerase III transcription, many of which are still poorly characterized. Most of the TFIIIC1 activities can be purified as part of a holoTFIIIC complex by immunopurification of TFIIIC2 from a cell line expressing tagged TFIIIC220 (Wang and Roeder 1998). One of them, called TFIIIC1 (as opposed to the TFIIIC1 fraction), remains associated with TFIIIC2 after further purification of the immunoprecipitated complex on a sucrose gradient and consists of at least four polypeptides with apparent molecular masses of 70 ,
50, 45, and $40 \mathrm{kD}$ (Wang and Roeder 1998), whose identities have not yet been reported. This relatively stable TFIIIC1/TFIIIC2 complex is referred to as human TFIIIC (see Fig. 8). A TFIIIC1 activity purified by conventional chromatography, which may correspond to the four polypeptides, binds cooperatively with both TFIIIC2 and a TFIIIC2/TFIIIA complex, and the footprint displayed by TFIIIC2 and the TFIIIC1 activity on a tRNA gene extends over the A and B boxes (Oettel et al. 1997).

In addition to the TFIIIC1 factor, the TFIIIC1 fraction contains an uncharacterized factor that specifically enhances human U6 transcription and has been called TFIIICU (Oettel et al. 1998) as well as an activity that footprints, on its own, over the terminator region of the VAI gene and a tRNA gene (see Fig. 8; Wang and Roeder 1996; Oettel et al. 1997, 1998). The latter activity is also present in holo-TFIIIC but can be dissociated from the TFIIIC factor with $300 \mathrm{mM} \mathrm{KCl}$ (Wang et al. 2000). It has been purified by a combination of conventional and DNA affinity chromatography to near homogeneity, and corresponds to four groups of NF1 isoforms (Wang et al. 2000). NF1 was initially identified as a cellular factor required for efficient initiation of $\mathrm{Ad} 2$ replication (Nagata et al. 1982), and was later found to be involved in the expression of many cellular and viral genes. The purified activity gives rise to a footprint over the two VAI terminator regions that is identical to that observed with holoTFIIIC, consistent with the idea that holo-TFIIIC contains, at a minimum, TFIIIC1, TFIIIC2, and NF1 polypeptides (Fig. 8). The role of NF1 in RNA polymerase III transcription is further addressed below.

\section{Termination and recycling: does the end help the beginning?}

RNA polymerase III is unique among the eukaryotic RNA polymerases in recognizing a simple run of $\mathrm{T}$ residues as a termination signal. In a linear template, mutation or deletion of the termination signal results in the production of run-off transcripts. However, aberrant termination is not the only consequence of debilitating the terminator. Mutation of the run of $\mathrm{T}$ residues in the VAI gene diminished the efficiency of single- and multipleround transcription in a HeLa cell extract (Wang and Roeder 1996; Wang et al. 2000). Similarly, in an S. cerevisiae system in which RNA polymerase III was limiting, deletion of the terminator affected multiple-round transcription, although in this case single-round transcription was not affected (Dieci and Sentenac 1996). These results suggest that the run of $T$ residues can contribute to the efficiency of initiation and reinitiation, and therefore that it may play a role in RNA polymerase recycling. In higher eukaryotes, a number of factors have been implicated in efficient termination and RNA polymerase III recycling, including the La protein, NF1 polypeptides, DNA topoisomerase I, and PC4.

\section{La protein}

The first factor implicated in transcription termination and recycling was the La antigen (Gottlieb and Steitz 
1989a,b). La binds to the poly-U tail at the end of RNA polymerase III transcripts (Stefano 1984), and could be demonstrated to stimulate transcription in a system in which transcription complexes were (1) preassembled on immobilized templates; (2) allowed to undergo a single round of transcription in the presence of heparin and sarcosyl, which resulted in stripping of RNA polymerase III; (3) washed; and (4) incubated with either fresh RNA polymerase alone or RNA polymerase together with La. The effect could be attributed to improved transcript release and transcription reinitiation (Maraia 1996), and was abolished by phosphorylation of Ser 366 in La (Fan et al. 1997). On the other hand, however, depletion of La from crude $X$. laevis extracts did not affect RNA polymerase III transcription (Lin-Marq and Clarkson 1998). Thus, although La can clearly affect RNA polymerase III transcription in certain in vitro systems, it is not clear that the protein plays such a role in the cell.

\section{NF1 polypeptides}

Other factors implicated in transcription termination and efficiency are the NF1 polypeptides in the TFIIIC1 fraction, which footprint over the VAI terminator region (Wang et al. 2000). NF1 polypeptides form a family of proteins with multiple functions encoded by a large number of alternatively spliced RNAs derived from four different genes. Individual NF1 proteins can dimerize with themselves and with other NF1 variants, but all variants have the same DNA-binding specificity and recognize the consensus sequence 5'-YTGGCANNNTGC CAR-3'. Sequences that closely match this consensus are found in the two VAI terminators, immediately downstream of the run of $\mathrm{T}$ residues, and mutations in these NF1-binding sites resulted in the appearance of read-through transcripts, although the effect was not as severe as with mutation of the run of $\mathrm{T}$ residues. Furthermore, addition of NF1 together with the TFIIIC factor improved the ratio of correctly terminated transcripts over read-through transcripts derived from a dC-tailed template, in which RNA polymerase III initiates transcription at the $\mathrm{dC}$ tail in the absence of transcription initiation factors (Wang et al. 2000). Together, these results suggest an involvement of NF1 polypeptides in transcription termination, although the interpretation of the dC-tailed template experiment is complicated by the fact that initiation at tailed templates tends to result in the production of RNA-DNA hybrids, which are known to inhibit transcription termination by RNA polymerase III (Campbell and Setzer 1992).

In addition to a qualitative effect on transcription termination, NF1 polypeptides can affect transcription efficiency. Thus, depletion of NF1 polypeptides from an extract severely reduced VAI transcription, and efficient transcription could be restored by addition of either purified NF1 activity or recombinant CTF1, the largest NF1 variant derived from the NF1-C gene (Santoro et al. 1988). However, in a highly purified transcription system, the stimulatory effect of NF1 was reportedly not observed, suggesting that NF1 serves to counteract nega- tive factors not present in the purified system (Wang et al. 2000). Thus, NF1 can increase VAI transcription efficiency in a crude extract, perhaps by facilitating transcription termination.

Depletion of NF1 reportedly also reduced transcription from the 5S RNA, a tRNA, and the human U6 snRNA genes, suggesting that NF1 polypeptides are generally required for efficient RNA polymerase III transcription in crude extracts (Wang et al. 2000). It is not clear, however, how NF1 is recruited to other RNA polymerase III terminators with no obvious NF1-binding sites close to the run of $\mathrm{T}$ residues. Perhaps in these cases, protein-protein interactions with TFIIIC2 (or, for genes such as the human U6 snRNA gene that do not recruit TFIIIC2, some other transcription factor) mediate NF1 recruitment.

\section{DNA topoisomerase I and PC4}

Like NF1, both DNA topoisomerase I and PC4 can suppress read-through transcripts in the dC-tailed template assay (Wang and Roeder 1998; Wang et al. 2000). However, these factors seem to differ from NF1 in that even though they enhance TFIIIC interactions in the downstream region of a tRNA gene and the VAI gene, they do not generate a footprint on their own, and the footprint observed in the presence of TFIIIC does not appear to extend over the termination region (Wang and Roeder 1998; Wang et al. 2000). DNA topoisomerase I and PC4 are present in holo-TFIIIC, but unlike NF1, they are present only in trace amounts. Thus, DNA topoisomerase I and PC4 seem less likely than NF1 to participate in RNA polymerase III transcription in vivo.

\section{Conclusion}

The study of RNA polymerase III promoters has provided perhaps the best illustration of how promoters with different structures rely differently on DNA-protein and protein-protein contacts to recruit, ultimately, the same RNA polymerase. Thus, TFIIIB can be recruited to a TATA box through direct binding to DNA, or to many DNA sequences through binding to TFIIIC. TFIIIC itself can bind directly to the B box of type 2 promoters or can use the accessory factor TFIIIA to bind to type 1 promoters. And in type 3 promoters, TFIIIB is recruited through a combination of DNA contacts with the TATA box and protein contacts with SNAP $_{\mathrm{c}}$. These promoters also illustrate how a transcription machinery has diversified and expanded from $S$. cerevisiae with its relatively simple genome to higher eukaryotes with their much more complex genomes to include new factors, such as $\mathrm{SNAP}_{\mathrm{c}}$, or multiple variations of a factor unique in yeast, such as HsBrf1 and HsBrf2.

RNA polymerase III transcription is tightly regulated; it is controlled by growth conditions, during the cell cycle, and by a number of viruses (for review, see Brown et al. 2000). These controls involve RNA polymerase III transcription factors, in particular TFIIIC2 and TFIIIB, as well as, perhaps, RNA polymerase III itself. For example, 
the ratio of active TFIIIC2a versus inactive TFIIIC $2 b$ is altered by the Ad2 E1A protein and the SV40 large T antigen (Brown et al. 2000). TFIIIB activity is regulated by a number of factors including P53 and retinoblastoma protein (Brown et al. 2000), as well as CK2, both in yeast and human cells (Ghavidel and Schultz 2001; Johnston et al. 2002). And in yeast, RNA polymerase III can be found associated with Maf1, a negative regulator of RNA polymerase III transcription (Pluta et al. 2001). So far, reconstitution of RNA polymerase III transcription with completely defined (recombinant) transcription factors has been achieved only in the $S$. cerevisiae system with a promoter that can recruit TFIIIB directly through a TATA box. An urgent task, which will allow a detailed understanding of the mechanisms by which RNA polymerase III transcription is regulated, is a description of the complete set of transcription factors sufficient for RNA polymerase III transcription from more complex promoters, both in naked DNA and in chromatin templates.

\section{Acknowledgments}

We thank Winship Herr, Ping Hu, David R. Setzer, Ian Willis, and the reviewers for comments that greatly improved the manuscript; and J. Duffy and P. Renna for artwork and photography. This work was funded in part by NIH grant GM38810. N.H. and L.S. are supported by the Howard Hughes Medical Institute.

\section{References}

Aasland, R., Stewart, A.F., and Gibson, T. 1996. The SANT domain: A putative DNA-binding domain in the SWI-SNF and ADA complexes, the transcriptional co-repressor N-CoR and TFIIIB. TIBS 21: 87-88.

Allison, D.S., Goh, S.H., and Hall, B.D. 1983. The promoter sequence of a yeast tRNA ${ }^{\text {tyr }}$ gene. Cell 34: 655-664.

Andrau, J.C., Sentenac, A., and Werner, M. 1999. Mutagenesis of yeast TFIIIB70 reveals C-terminal residues critical for interaction with TBP and C34. J. Mol. Biol. 288: 511-520.

Arakawa, H., Nagase, H., Hayashi, N., Ogawa, M., Nagata, M., Fujiwara, T., Takahashi, E., Shin, S., and Nakamura, Y. 1995 Molecular cloning, characterization, and chromosomal mapping of a novel human gene (GTF3A) that is highly homologous to Xenopus transcription factor IIIA. Cytogenet. Cell. Genet. 70: 235-238.

Arrebola, R., Manaud, N., Rozenfeld, S., Marsolier, M.-C., Lefebvre, O., Carles, C., Thuriaux, P., Conesa, C., and Sentenac, A. 1998. $\tau 91$, an essential subunit of yeast transcription factor IIIC, cooperates with $\tau 138$ in DNA binding. Mol. Cell. Biol. 18: 1-9.

Babb, R., Cleary, M.A., and Herr, W. 1997. OCA-B is a functional analog of VP16 but targets a separate surface of the Oct-1 POU domain. Mol. Cell. Biol. 17: 7295-7305.

Baer, M., Nilsen, T.W., Costigan, C., and Altman, S. 1989. Structure and transcription of a human gene for H1 RNA, the RNA component of human RNase P. Nucleic Acids Res. 18: 97-103.

Bagby, S., Kim, S., Maldonado, E., Tong, K.I., Reinberg, D., and Ikura, M. 1995. Solution structure of the C-terminal core domain of human TFIIB: Similarity to cyclin A and interac- tion with TATA-binding protein. Cell 82: 857-867.

Bai, L., Wang, Z., Yoon, J.-B., and Roeder, R.G. 1996. Cloning and characterization of the $\mathrm{b}$ subunit of human proximal sequence element-binding transcription factor and its involvement in transcription of small nuclear RNA genes by RNA polymerases II and III. Mol. Cell. Biol. 16: 5419-5426.

Barberis, A., Müller, C.W., Harrison, S.C., and Ptashne, M. 1993. Delineation of two functional regions of transcription factor TFIIB. Proc. Natl. Acad. Sci. 90: 5628-5632.

Bartholomew, B., Kassavetis, G.A., and Geiduschek, E.P. 1990. The subunit structure of Saccharomyces cerevisiae transcription factor IIIC probed with a novel photocrosslinking reagent. EMBO I. 9: 2197-2205.

1991. Two components of Saccharomyces cerevisiae transcription factor IIIB (TFIIIB) are stereospecifically located upstream of a tRNA gene and interact with the secondlargest subunit of TFIIIC. Mol. Cell. Biol. 11: 5181-5189.

Bartholomew, B., Durkovich, D., Kassavetis, G.A., and Geiduschek, E.P. 1993. Orientation and topography of RNA polymerase III in transcription complexes. Mol. Cell. Biol. 13: 942-952.

Bieker, J.J., Martin, P.L., and Roeder, R.G. 1985. Formation of a rate-limiting intermediate in 5S RNA gene transcription. Cell 40: 119-127.

Bogenhagen, D.F. 1985. The intragenic control region of the Xenopus 5 S RNA gene contains two factor A binding domains that must be aligned properly for efficient transcription initiation. J. Biol. Chem. 260: 6466-6471.

Bogenhagen, D.F., Sakonju, S., and Brown, D.D. 1980. A control region in the center of the 5S RNA gene directs specific initiation of transcription: II. The 3 ' border of the region. Cell 19: 27-35.

Bogenhagen, D.F., Wormington, W.M., and Brown, D.D. 1982. Stable transcription complexes of Xenopus 5S RNA genes: A means to maintain the differentiated state. Cell 28: 413-421.

Braun, B.R., Bartholomew, B., Kassavetis, G.A., and Geiduschek, E.P. 1992a. Topography of transcription factor complexes on the Saccharomyces cerevisiae 5 S RNA gene. I. Mol. Biol. 228: 1063-1077.

Braun, B.R., Kassavetis, G.A., and Geiduschek, E.P. 1992 b. Bending of the Saccharomyces cerevisiae 5S rRNA gene in transcription factor complexes. J. Biol. Chem. 267: 2256222569.

Brow, D.A. and Guthrie, C. 1990. Transcription of a yeast U6 snRNA gene requires a polymerase III promoter element in a novel position. Genes \& Dev. 4: 1345-1356.

Brown, T.R., Scott, P.H., Stein, T., Winter, A.G., and White, R.J. 2000. RNA polymerase III transcription: Its control by tumor suppressors and its deregulation by transforming agents. Gene Expr. 9: 15-28.

Brun, I., Sentenac, A., and Werner, M. 1997. Dual role of the C34 subunit of RNA polymerase III in transcription initiation. EMBO T. 16: 5730-5741.

Buratowski, S. and Zhou, H. 1992. A suppressor of TBP mutations encodes an RNA polymerase III transcription factor with homology with TFIIB. Cell 71: 221-230.

Cabart, P. and Murphy, S. 2001. BRFU, a TFIIB-like factor, is directly recruited to the TATA-box of polymerase III small nuclear RNA gene promoters through its interaction with TATA-binding protein. J. Biol. Chem. 276: 43056-43064.

. 2002. Assembly of human snRNA gene-specific TFIIIB complex de novo on and off promoter. I. Biol. Chem. 277: 26831-26838.

Camier, S., Dechampesme, A.M., and Sentenac, A. 1995. The only essential function of TFIIIA in yeast is the transcription of 5S rRNA genes. Proc. Nat1. Acad. Sci. 92: 9338-9342. 
Campbell Jr., F.E., and Setzer, D.R. 1992. Transcription termination by RNA polymerase III: Uncoupling of polymerase release from termination signal recognition. Mol. Cell. Biol. 12: $2260-2272$.

Challice, J.M. and Segall, J. 1989. Transcription of the 5 S rRNA gene of Saccharomyces cerevisiae requires a promoter element at +1 and a 14-base pair internal control region. J. Biol. Chem. 264: 20060-20067.

Chasman, D., Cepek, K., Sharp, P.A., and Pabo, C.O. 1999. Crystal structure of an OCA-B peptide bound to an Oct-1 POU domain/octamer DNA complex: Specific recognition of a protein-DNA interface. Genes \& Dev. 13: 2650-2657.

Chaussivert, N., Conesa, C., Shaaban, S., and Sentenac, A. 1995. Complex interactions between yeast TFIIIB and TFIIIC. I. Biol. Chem. 270: 15353-15358.

Chedin, S., Ferri, M.L., Peyroche, G., Andrau, J.C., Jourdain, S., Lefebvre, O., Werner, M., Carles, C., and Sentenac, A. 1998. The yeast RNA polymerase III transcription machinery: A paradigm for eukaryotic gene activation. Cold Spring Harb. Symp. Quant. Biol. 63: 381-389.

Chiang, C.-M., Ge, H., Wang, Z., Hoffman, A., and Roeder, R.G. 1993. Unique TATA-binding protein-containing complexes and cofactors involved in transcription by RNA polymerases II and III. EMBO J. 12: 2749-2762.

Choder, M. and Young, R.A. 1993. A portion of RNA polymerase II molecules has a component essential for stress responses and stress survival. Mol. Cell. Biol. 13: 6984-6991.

Ciliberto, G., Raugei, G., Costanzo, F., Dente, L., and Cortese, R. 1983. Common and interchangeable elements in the promoters of genes transcribed by RNA polymerase III. Cell 32: $725-733$.

Clark, M.E., Hammerle, T., Wimmer, E., and Dasgupta, A. 1991. Poliovirus proteinase $3 \mathrm{C}$ converts an active form of transcription factor IIIC to an inactive form: A mechanism for inhibition of host cell polymerase III transcription by poliovirus. EMBO J. 10: 2941-2947.

Clemens, K.R., Liao, X., Wolf, V., Wright, P.E., and Gottesfeld, J.M. 1992. Definition of the binding sites of individual zinc fingers in the transcription factor IIIA-5S RNA gene complex. Proc. Natl. Acad. Sci. 89: 10822-10826.

Cloutier, T.E., Librizzi, M.D., Mollah, A.K., Brenowitz, M., and Willis, I.M. 2001. Kinetic trapping of DNA by transcription factor IIIB. Proc. Nat1. Acad. Sci. 98: 9581-9586.

Colbert, T. and Hahn, S. 1992. A yeast TFIIB-related factor involved in RNA polymerase III transcription. Genes \& Dev. 6: 1940-1949.

Colbert, T., Lee, S., Schimmack, G., and Hahn, S. 1998. Architecture of protein and DNA contacts within the TFIIIBDNA complex. Mol. Cell. Biol. 18: 1682-1691.

Cormack, B.P. and Struhl, K. 1992. The TATA-binding protein is required for transcription by all three nuclear RNA polymerases in yeast cells. Cell 69: 685-696.

Darby, M.K., Andrews, M.T., and Brown, D.D. 1988. Transcription complexes that program Xenopus 5S RNA genes are stable in vivo. Proc. Natl. Acad. Sci. 85: 5516-5520.

Das, A.K., Cohen, P.W., and Barford, D. 1998. The structure of the tetratricopeptide repeats of protein phosphatase 5: Implications for TPR-mediated protein-protein interactions. EMBO J. 17: 1192-1199.

Das, G., Henning, D., Wright, D., and Reddy, R. 1988. Upstream regulatory elements are necessary and sufficient for transcription of a U6 gene by RNA polymerase III. EMBO $I$. 7: 503-512.

Das, G., Hinkley, C.S., and Herr, W. 1995. Basal promoter elements as a selective determinant of transcriptional activator function. Nature 374: 657-660.
Deprez, E., Arrebola, R., Conesa, C., and Sentenac, A. 1999. A subunit of yeast TFIIIC participates in the recruitment of TATA-binding protein. Mol. Cell. Biol. 19: 8042-8051.

Dieci, G. and Sentenac, A. 1996. Facilitated recycling pathway for RNA polymerase III. Cell 84: 245-252.

Dieci, G., Percudani, R., Giuliodori, S., Bottarelli, L., and Ottonello, S. 2000. TFIIIC-independent in vitro transcription of yeast tRNA genes. J. Mol. Biol. 299: 601-613.

Dumay, H., Rubbi, L., Sentenac, A., and Marck, C. 1999. Interaction between yeast RNA polymerase III and transcription factor TFIIIC via $\mathrm{ABC} 10 \alpha$ and $\tau 131$ subunits. J. Biol. Chem. 274: 33462-33468.

Dumay-Odelot, H., Acker, J., Arrebola, R., Sentenac, A., and Marck, C. 2002. Multiple roles of the $\tau 131$ subunit of yeast transcription factor IIIC (TFIIIC) in TFIIIB assembly. Mol. Cell. Biol. 22: 298-308.

Edwards, A.M., Kane, C.M., Young, R.A., and Kornberg, R.D. 1991. Two dissociable subunits of yeast RNA polymerase II stimulate the initiation of transcription at a promoter in vitro. J. Biol. Chem. 266: 71-75.

Engelke, D.R., Ng, S.Y., Shastry, B.S., and Roeder, R.G. 1980 Specific interaction of a purified transcription factor with an internal control region of 5S RNA genes. Cell 19: 717-728.

Eschenlauer, J.B., Kaiser, M.W., Gerlach, V.L., and Brow, D.A. 1993. Architecture of a yeast U6 RNA gene promoter. Mol. Cell. Biol. 13: 3015-3026.

Fan, H., Sakulich, A.L., Goodier, J.L., Zhang, X., Qin, J., and Maraia, R.J. 1997. Phosphorylation of the human La antigen on serine 366 can regulate recycling of RNA polymerase III transcription complexes. Cell 88: 707-715.

Ferri, M.L., Peyroche, G., Siaut, M., Lefebvre, O., Carles, C., Conesa, C., and Sentenac, A. 2000. A novel subunit of yeast RNA polymerase III interacts with the TFIIB-related domain of TFIIIB70. Mol. Cell. Biol. 20: 488-495.

Flores, A., Briand, J.F., Gadal, O., Andrau, J.C., Rubbi, L., Van Mullem, V., Boschiero, C., Goussot, M., Marck, C., Carles, C., et al. 1999. A protein-protein interaction map of yeast RNA polymerase III. Proc. Natl. Acad. Sci. 96: 7815-7820.

Ford, E., Strubin, M., and Hernandez, N. 1998. The Oct-1 POU domain activates snRNA gene transcription by contacting a region in the $\operatorname{SNAP}_{c}$ largest subunit that bears sequence similarities to the Oct-1 coactivator OBF-1. Genes \& Dev. 12: 3528-3540.

Fowlkes, D.M. and Shenk, T. 1980. Transcriptional control regions of the adenovirus VAI RNA gene. Cell 22: 405-413.

Gabrielsen, O.S., Marzouki, N., Ruet, A., Sentenac, A., and Fromageot, P. 1989. Two polypeptide chains in yeast transcription factor $\tau$ interact with DNA. J. Biol. Chem. 264: 75057511.

Galli, G., Hofstetter, H., and Birnstiel, M.L. 1981. Two conserved sequence blocks within eukaryotic tRNA genes are major promoter elements. Nature 294: 626-631.

Geiduschek, E.P. and Kassavetis, G.A. 2001. The RNA polymerase III transcription apparatus. J. Mol. Biol. 310: 1-26.

Ghavidel, A. and Schultz, M.C. 2001. TATA binding proteinassociated CK2 transduces DNA damage signals to the RNA polymerase III transcriptional machinery. Cell 106: 575-584.

Ghavidel, A., Hockman, D.J., and Schultz, M.C. 1999. A review of progress towards elucidating the role of protein kinase CK2 in polymerase III transcription: Regulation of the TATA binding protein. Mol. Cell. Biochem. 191: 143-148.

Ginsberg, A.M., King, B.O., and Roeder, R.G. 1984. Xenopus 5S gene transcription factor, TFIIIA: Characterization of a cDNA clone and measurement of RNA levels throughout development. Cell 39: 479-489.

Gottlieb, E. and Steitz, J.A. 1989a. Function of the mammalian 
La protein: Evidence for its action in transcription termination by RNA polymerase III. EMBO J. 8: 851-861.

- 1989b. The RNA binding protein La influences both the accuracy and the efficiency of RNA polymerase III transcription in vitro. $E M B O J$. 8: 841-850.

Grove, A., Kassavetis, G.A., Johnson, T.E., and Geiduschek, E.P. 1999. The RNA polymerase III-recruiting factor TFIIIB induces a DNA bend between the TATA box and the transcriptional start site. J. Mol. Biol. 285: 1429-1440.

Ha, I., Roberts, S., Maldonado, E., Sun, X., Green, M., and Reinberg, D. 1993. Multiple functional domains of human transcription factor IIB. Distinct interactions with two general transcription factors and RNA polymerase II. Genes \& Dev. 7: 1021-1032.

Hahn, S. and Roberts, S. 2000. The zinc ribbon domains of the general transcription factors TFIIB and Brf: Conserved functional surfaces but different roles in transcription initiation. Genes \& Dev. 14: 719-730.

Hamada, M., Huang, Y., Lowe, T.M., and Maraia, R.J. 2001. Widespread use of TATA elements in the core promoters for RNA polymerases III, II and I in fission yeast. Mol. Cell. Biol. 21: 6870-6881.

Henry, R.W., Sadowski, C.L., Kobayashi, R., and Hernandez, N. 1995. A TBP-TAF complex required for transcription of human snRNA genes by RNA polymerases II and III. Nature 374: 653-657.

Henry, R.W., Ma, B., Sadowski, C.L., Kobayashi, R., and Hernandez, N. 1996. Cloning and characterization of SNAP50, a subunit of the snRNA-activating protein complex $\mathrm{SNAP}_{\mathrm{c}}$. EMBO J. 15: 7129-7136.

Henry, R.W., Ford, E., Mital, R., Mittal, V., and Hernandez, N. 1998a. Crossing the line between RNA polymerases: Transcription of human snRNA genes by RNA polymerases II and III. In Mechanisms of Transcription. Cold Spring Harbor Symposia on Quantitative Biology Vol. LXIII, pp. 111-120. Cold Spring Harbor Laboratory Press, Cold Spring Harbor, NY.

Henry, R.W., Mittal, V., Ma, B., Kobayashi, R., and Hernandez, N. 1998b. SNAP19 mediates the assembly of a functional core promoter complex $\left(\mathrm{SNAP}_{\mathrm{c}}\right)$ shared by RNA polymerases II and III. Genes \& Dev. 12: 2664-2672.

Hernandez, N. 1992. Transcription of vertebrate snRNA genes and related genes. In Transcriptional regulation (eds. S.L. McKnight and K.R. Yamamoto), pp. 281-313. Cold Spring Harbor Laboratory Press, Cold Spring Harbor, New York.

- 2001. snRNA genes: A model system to study fundamental mechanisms of transcription. J. Biol. Chem. 276: 26733-26736.

Hernandez, N. and Lucito, R. 1988. Elements required for transcription initiation of the human U2 snRNA gene coincide with elements required for snRNA $3^{\prime}$ end formation. $E M B O$ J. 7: 3125-3134.

Herr, W. and Cleary, M.A. 1995. The POU domain: Versatility in transcriptional regulation by a flexible two-in-one DNAbinding domain. Genes \& Dev. 9: 1679-1693.

Hisatake, K., Roeder, R.G., and Horikoshi, M. 1993. Functional dissection of TFIIB domains required for TFIIB-TFIID-promoter complex formation and basal transcription activity. Nature 363: 744-747.

Hofstetter, H., Kressman, A., and Birnstiel, M.L. 1981. A split promoter for a eucaryotic tRNA gene. Cell 24: 573-585.

Holstege, F.C.P., van der Vliet, P.C., and Timmers, H.T.M. 1996. Opening of an RNA polymerase II promoter occurs in two distinct steps and requires the basal transcription factors IIE and IIH. EMBO J. 15: 1666-1677.

Hsieh, Y.J., Kundu, T.K., Wang, Z., Kovelman, R., and Roeder,
R.G. 1999a. The TFIIIC90 subunit of TFIIIC interacts with multiple components of the RNA polymerase III machinery and contains a histone-specific acetyltransferase activity. Mol. Cell. Biol. 19: 7697-7704.

Hsieh, Y.J., Wang, Z., Kovelman, R., and Roeder, R.G. 1999b. Cloning and characterization of two evolutionarily conserved subunits (TFIIIC102 and TFIIIC63) of human TFIIIC and their involvement in functional interactions with TFIIIB and RNA polymerase III. Mol. Cell. Biol. 19: 4944-4952.

$\mathrm{Hu}, \mathrm{P} ., \mathrm{Wu}, \mathrm{S}$., Sun, Y., Yuan, C.-C., Kobayashi, R., Myers, M.P., and Hernandez, N. 2002. The characterization of human RNA polymerase III identifies orthologues for yeast RNA polymerase III subunits. Mol. Cell. Biol. (In press).

Huang, W., Wong, J.M., and Bateman, E. 1996. TATA elements direct bi-directional transcription by RNA polymerases II and III. Nucleic Acids Res. 24: 1158-1163.

Huang, Y. and Maraia, R.J. 2001. Comparison of the RNA polymerase III transcription machinery in Schizosaccharomyces pombe, Saccharomyces cerevisiae and human. Nucleic Acids Res. 29: 2675-2690.

Huang, Y., Hamada, M., and Maraia, R.J. 2000. Isolation and cloning of four subunits of a fission yeast TFIIIC complex that includes an ortholog of the human regulatory protein TFIIICß. J. Biol. Chem. 275: 31480-31487.

Huet, J. and Sentenac, A. 1992. The TATA-binding protein participates in TFIIIB assembly on tRNA genes. Nucleic Acids Res. 20: 6451-6454.

Ittmann, M., Ali, J., Greco, A., and Basilico, C. 1993. The gene complementing a temperature-sensitive cell cycle mutant of BHK cells is the human homologue of the yeast RPC53 gene, which encodes a subunit of RNA polymerase C (III). Cell Growth Differ. 4: 503-511.

Jackson, A.J., Ittmann, M., and Pugh, B.F. 1995. The BN51 protein is a polymerase (Pol)-specific subunit of RNA Pol III which reveals a link between Pol III transcription and prerRNA processing. Mol. Cell. Biol. 15: 94-101.

Joazeiro, C.A., Kassavetis, G.A., and Geiduschek, E.P. 1994. Identical components of yeast transcription factor IIIB are required for transcription of TATA box-containing and TATA-less genes. Mol. Cell. Biol. 14: 2798-2808.

- 1996. Alternative outcomes in assembly of promoter complexes: The roles of TBP and a flexible linker in placing TFIIIB on tRNA genes. Genes \& Dev. 10: 725-739.

Johnston, I.M., Allison, S.J., Morton, J.P., Schramm, L., Scott, P.H., and White, R.J. 2002. CK2 forms a stable complex with TFIIIB and activates RNA polymerase III transcription in human cells. Mol. Cell. Biol. 22: 3757-3768.

Kassavetis, G.A., Riggs, D.L., Negri, R., Nguyen, L.H., and Geiduschek, E.P. 1989. Transcription factor IIIB generates extended DNA interactions in RNA polymerase III transcription complexes on tRNA genes. Mol. Cell. Biol. 9: 25512566.

Kassavetis, G.A., Braun, B.R., Nguyen, L.H., and Geiduschek, E.P. 1990. S. cerevisiae TFIIIB is the transcription initiation factor proper of RNA polymerase III, while TFIIIA and TFIIIC are assembly factors. Cell 60: 235-245.

Kassavetis, G.A., Bartholomew, B., Blanco, J.A., Johnson, T.E., and Geiduschek, P.E. 1991. Two essential components of the Saccharomyces cerevisiae transcription factor TFIIIB: Transcription and DNA-binding properties. Proc. Natl. Acad. Sci. 88: 7308-7312.

Kassavetis, G.A., Joazeiro, C.A.P., Pisano, M., Geiduschek, P.E., Colbert, T., Hahn, S., and Blanco, J.A. 1992. The role of the TATA-binding protein in the assembly and function of the multisubunit yeast RNA polymerase III transcription factor, TFIIIB. Cell 71: 1055-1064. 
Kassavetis, G.A., Nguyen, S.T., Kobayashi, R., Kumar, A., Geiduschek, E.P., and Pisano, M. 1995. Cloning, expression, and function of TFC5, the gene encoding the $\mathrm{B}^{\prime \prime}$ component of the Saccharomyces cerevisiae RNA polymerase III transcription factor TFIIIB. Proc. Nat1. Acad. Sci. 92: 9786-9790.

Kassavetis, G.A., Bardeleben, C., Kumar, A., Ramirez, E., and Geiduschek, E.P. 1997. Domains of the Brf component of RNA polymerase III transcription factor IIIB (TFIIIB): Functions in assembly of TFIIIB-DNA complexes and recruitment of RNA polymerase to the promoter. Mol. Cell. Biol. 17: 5299-5306.

Kassavetis, G.A., Kumar, A., Letts, G., and Geiduschek, E.P. 1998a. A post-recruitment function for the RNA polymerase III transcription-initiation factor IIIB. Proc. Natl. Acad. Sci. 95: 9196-9201.

Kassavetis, G.A., Kumar, A., Ramirez, E., and Geiduschek, E.P. 1998b. Functional and structural organization of Brf, the TFIIB-related component of the RNA polymerase III transcription initiation complex. Mol. Cell. Biol. 18: 5587-5599.

Kassavetis, G.A., Letts, G.A., and Geiduschek, E.P. 1999. A minimal RNA polymerase III transcription system. EMBO $J$. 18: 5042-5051.

Kehres, D.G., Subramanyan, G.S., Hung, V.S., Rogers Jr., G.W., and Setzer, D.R. 1997. Energetically unfavorable interactions among the zinc fingers of transcription factor IIIA when bound to the $5 \mathrm{~S}$ rRNA gene. J. Biol. Chem. 272: 20152-20161.

Kelter, A.R., Herchenbach, J., and Wirth, B. 2000. The transcription factor-like nuclear regulator (TFNR) contains a novel 55 -amino-acid motif repeated nine times and maps closely to SMN1. Genomics 70: 315-326.

Khazak, V., Estojak, J., Cho, H., Majors, J., Sonoda, G., Testa, J.R., and Golemis, E.A. 1998. Analysis of the interaction of the novel RNA polymerase II (Pol II) subunit hsRPB4 with its partner hsRPB7 and with Pol II. Mol. Cell. Biol. 18: 19351945.

Khoo, B., Brophy, B., and Jackson, S.P. 1994. Conserved functional domains of the RNA polymerase III general transcription factor BRF. Genes \& Dev. 8: 2879-2890.

Kovelman, R. and Roeder, R.G. 1992. Purification and characterization of two forms of human transcription factor IIIC. J. Biol. Chem. 267: 24446-24456.

Krol, A., Carbon, P., Ebel, J.-P., and Appel, B. 1987. Xenopus tropicalis U6 snRNA genes transcribed by Pol III contain the upstream promoter elements used by Pol II dependent UsnRNA genes. Nucleic Acids Res. 15: 2463-2478.

Kumar, A., Kassavetis, G.A., Geiduschek, E.P., Hambalko, M., and Brent, C.J. 1997. Functional dissection of the B" component of RNA polymerase III transcription factor IIIB: A scaffolding protein with multiple roles in assembly and initiation of transcription. Mol. Cell. Biol. 17: 1868-1880.

Kundu, T.K., Wang, Z., and Roeder, R.G. 1999. Human TFIIIC relieves chromatin-mediated repression of RNA polymerase III transcription and contains an intrinsic histone acetyltransferase activity. Mol. Cell. Biol. 19: 1605-1615.

Kunkel, G.R. and Pederson, T. 1988. Upstream elements required for efficient transcription of a human U6 RNA gene resemble those of U1 and U2 genes even though a different polymerase is used. Genes \& Dev. 2: 196-204.

- 1989. Transcription of a human U6 small nuclear RNA gene in vivo withstands deletion of intragenic sequences but not of an upstream TATATA box. Nucleic Acids Res. 17: 7371-7379.

Lagna, G., Kovelman, R., Sukegawa, J., and Roeder, R.G. 1994. Cloning and characterization of an evolutionary divergent DNA-binding subunit of mammalian TFIIIC. Mol. Cell. Biol.
14: 3053-3064.

Lassar, A.B., Martin, P.L., and Roeder, R.G. 1983. Transcription of class III genes: Formation of preinitiation complexes. Science 222: 740-748.

Lefebvre, O., Carles, C., Conesa, C., Swanson, R.N., Bouet, F., Riva, M., and Sentenac, A. 1992. TFC3: Gene encoding the B-block binding subunit of the yeast transcription factor IIIC. Proc. Natl. Acad. Sci. 89: 10512-10516.

L'Etoile, N.D., Fahnestock, M.L., Shen, Y., Aebersold, R., and Berk, A.J. 1994. Human transcription factor IIIC box B binding subunit. Proc. Natl. Acad. Sci. 91: 1652-1656.

Leveillard, T., Kassavetis, G.A., and Geiduschek, E.P. 1991. Saccharomyces cerevisiae transcription factors IIIB and IIIC bend the DNA of a tRNA ${ }^{\text {Gln }}$ gene. J. Biol. Chem. 266: 51625168.

Liao, X.B., Clemens, K.R., Tennant, L., Wright, P.E., and Gottesfeld, J.M. 1992. Specific interaction of the first three zinc fingers of TFIIIA with the internal control region of the Xenopus 5 S RNA gene. J. Mol. Biol. 223: 857-871.

Lin-Marq, N. and Clarkson, S.G. 1998. Efficient synthesis, termination and release of RNA polymerase III transcripts in Xenopus extracts depleted of La protein. EMBO J. 17: 20332041.

Lobo, S. and Hernandez, N. 1989. A 7 bp mutation converts a human RNA polymerase II snRNA promoter into an RNA polymerase III promoter. Cell 58: 55-67.

Lobo, S.M., Lister, J., Sullivan, M.L., and Hernandez, N. 1991. The cloned RNA polymerase II transcription factor IID selects RNA polymerase III to transcribe the human U6 gene in vitro. Genes \& Dev. 5: 1477-1489.

Lobo, S.M., Tanaka, M., Sullivan, M.L., and Hernandez, N. 1992. A TBP complex essential for transcription from TATA-less but not TATA-containing RNA polymerase III promoters is part of the TFIIIB fraction. Cell 71: 1029-1040.

López-De-León, A., Librizzi, M., Puglia, K., and Willis, I.M. 1992. PCF4 encodes an RNA polymerase III transcription factor with homology to TFIIB. Cell 71: 211-220.

$\mathrm{Ma}, \mathrm{B}$. and Hernandez, N. 2000. A map of protein-protein contacts within the snRNA activating protein complex $\mathrm{SNAP}_{\mathrm{c}}$. J. Biol. Chem. 276: 5027-5035.

. 2002. Redundant cooperative interactions for assembly of a human U6 transcription initiation complex. Mol. Cell. Biol. (In press).

Mach, C.M., Hargrove, B.W., and Kunkel, G.R. 2002. The small RNA gene activator protein, SphI postoctamer homologybinding factor/selenocysteine tRNA gene transcription activating factor, stimulates transcription of the human interferon regulatory factor-3 gene. J. Biol. Chem. 277: 48534858.

Manaud, N., Arrebola, R., Buffin-Meyer, B., Lefebvre, O., Voss, H., Riva, M., Conesa, C., and Sentenac, A. 1998. A chimeric subunit of yeast transcription factor IIIC forms a subcomplex with $\tau 95$. Mol. Cell. Biol. 18: 3191-3200.

Mao, X. and Darby, M.K. 1993. A position-dependent transcription-activating domain in TFIIIA. Mol. Cell. Biol. 13: 74967506.

Maraia, R.J. 1996. Transcription termination factor La is also an initiation factor for RNA polymerase III. Proc. Natl. Acad. Sci. 93: 3383-3387.

Marck, C., Lefebvre, O., Carles, C., Riva, M., Chaussivert, N., Ruet, A., and Sentenac, A. 1993. The TFIIIB-assembling subunit of yeast transcription factor TFIIIC has both tetratricopeptide repeats and basic helix-loop-helix motifs. Proc. Natl. Acad. Sci. 90: 4027-4031.

Margottin, F., Dujardin, G., Gerard, M., Egly, J.-M., Huet, J., and Sentenac, A. 1991. Participation of the TATA factor in tran- 
scription of the yeast U6 gene by RNA polymerase C. Science 251: 424-426.

Marzouki, N., Camier, S., Ruet, A., Moenne, A., and Sentenac, A. 1986. Selective proteolysis defines two DNA binding domains in yeast transcription factor $\tau$. Nature 323: 176-178.

Mattaj, I.W., Dathan, N.A., Parry, H.W., Carbon, P., and Krol, A. 1988. Changing the RNA polymerase specificity of U snRNA gene promoters. Cell 55: 435-442.

McCulloch, V., Hardin, P., Peng, W., Ruppert, J.M., and LoboRuppert, S.M. 2000. Alternatively spliced hBRF variants function at different RNA polymerase III promoters. $E M B O$ J. 19: 4134-4143.

McKune, K., Richards, K.L., Edwards, A.M., Young, R.A., and Woychik, N.A. 1993. RPB7, one of two dissociable subunits of yeast RNA polymerase II, is essential for cell viability. Yeast 9: 295-299.

Meyers, R.E. and Sharp, P.A. 1993. TATA-binding protein and associated factors in polymerase II and polymerase III transcription. Mol. Cell. Biol. 13: 7953-7960.

Miller, J., McLachlan, A.D., and Klug, A. 1985. Repetitive zincbinding domains in the protein transcription factor IIIA from Xenopus oocytes. EMBO J. 4: 1609-1614.

Mital, R., Kobayashi, R., and Hernandez, N. 1996. RNA polymerase III transcription from the human U6 and Adenovirus type $2 \mathrm{VAI}$ promoters has different requirements for human BRF, a subunit of human TFIIIB. Mol. Cell. Biol. 16: 70317042.

Mitchell, M.T., Hobson, G.M., and Benfield, P.A. 1992. TATA box-mediated polymerase III transcription in vitro. J. Biol. Chem. 267: 1995-2005.

Mittal, V. and Hernandez, N. 1997. Role for the amino-terminal region of human TBP in U6 snRNA transcription. Science 275: 1136-1140.

Mittal, V., Cleary, M.A., Herr, W., and Hernandez, N. 1996. The Oct-1 POU-specific domain can stimulate small nuclear RNA gene transcription by stabilizing the basal transcription complex SNAP ${ }_{c}$. Mol. Cell. Biol. 16: 1955-1965.

Mittal, V., Ma, B., and Hernandez, N. 1999. SNAP : A core promoter factor with a built-in DNA-binding damper that is deactivated by the Oct-1 POU domain. Genes \& Dev. 13: 1807-1821.

Moir, R.D., Sethy-Coraci, I., Puglia, K., Librizzi, M.D., and Willis, I.M. 1997. A tetratricopeptide repeat mutation in yeast transcription factor IIIC131 (TFIIIC131) facilitates recruitment of TFIIB-related factor TFIIIB70. Mol. Cell. Biol. 17: 7119-7125.

Moir, R.D., Puglia, K.V., and Willis, I.M. 2000. Interactions between the tetratricopeptide repeat-containing transcription factor TFIIIC131 and its ligand, TFIIIB70. Evidence for a conformational change in the complex. J. Biol. Chem. 275: 26591-26598.

- 2002a. Autoinhibition of TFIIIB70 binding by the tetratricopeptide repeat-containing subunit of TFIIIC. J. Biol. Chem. 277: 694-701.

- 2002b. A gain-of-function mutation in the second tetratricopeptide repeat of TFIIIC131 relieves autoinhibition of Brf1 binding. Mol. Cell. Biol. 22: 6131-6141.

Murphy, S., Tripodi, M., and Melli, M. 1986. A sequence upstream from the coding region is required for the transcription of the 7SK RNA genes. Nucleic Acids Res. 14: 9243 9260.

Murphy, S., Yoon, J.-B., Gerster, T., and Roeder, R.G. 1992. Oct-1 and Oct-2 potentiate functional interactions of a transcription factor with the proximal sequence element of small nuclear RNA genes. Mol. Cell. Biol. 12: 3247-3261.

Nagata, K., Guggenheimer, R.A., Enomoto, T., Lichy, J.H., and
Hurwitz, J. 1982. Adenovirus DNA replication in vitro: Identification of a host factor that stimulates synthesis of the preterminal protein-dCMP complex. Proc. Natl. Acad. Sci. 79: 6438-6442.

Nguyen, V.T., Kiss, T., Michels, A.A., and Bensaude, O. 2001. 7SK small nuclear RNA binds to and inhibits the activity of CDK9/cyclin T complexes. Nature 414: 322-325.

Nikolov, D.B., Chen, H., Halay, E.D., Usheva, A.A., Hisatake, K., Lee, D.K., Roeder, R.G., and Burley, S.K. 1995. Crystal structure of a TFIIB-TBP-TATA-element ternary complex. Nature 377: 119-128.

Oettel, S., Hartel, F., Kober, I., Iben, S., and Seifart, K.H. 1997. Human transcription factors IIIC2, IIIC1 and a novel component IIIC0 fulfil different aspects of DNA binding to various Pol III genes. Nucleic Acids Res. 25: 2440-2447.

Oettel, S., Kober, I., and Seifart, K.H. 1998. The activity binding to the termination region of several Pol III genes represents a separate entity and is distinct from a novel component enhancing U6 snRNA transcription. Nucleic Acids Res. 26: 4324-4331.

Orlicky, S.M., Tran, P.T., Sayre, M.H., and Edwards, A.M. 2001 Dissociable Rpb4-Rpb7 subassembly of RNA polymerase II binds to single-strand nucleic acid and mediates a post-recruitment step in transcription initiation. J. Biol. Chem. 276: 10097-10102.

Orphanides, G., Lagrange, T., and Reinberg, D. 1996. The general transcription factors of RNA polymerase II. Genes \& Dev. 10: 2657-2683.

Ouyang, C., Martinez, M.J., Young, L.S., and Sprague, K.U. 2000. TATA-Binding protein-TATA interaction is a key determinant of differential transcription of silkworm constitutive and silk gland-specific tRNA ${ }^{\mathrm{Ala}}$ genes. Mol. Cell. Biol. 20: $1329-1343$.

Pardee, T.S., Bangur, C.S., and Ponticelli, A.S. 1998. The Nterminal region of yeast TFIIB contains two adjacent functional domains involved in stable RNA polymerase II binding and transcription start site selection. J. Biol. Chem. 273: 17859-17864.

Paule, M.R. and White, R.J. 2000. Survey and summary: Transcription by RNA polymerases I and III. Nucleic Acids Res. 28: $1283-1298$.

Pelham, H.R. and Brown, D.D. 1980. A specific transcription factor that can bind either the 5S RNA gene or 5S RNA. Proc. Nat1. Acad. Sci. 77: 4170-4174.

Pieler, T., Appel, B., Oei, S.L., Mentzel, H., and Erdmann, V.A. 1985a. Point mutational analysis of the Xenopus laevis 5S gene promoter. $E M B O$ J. 4: 1847-1853.

Pieler, T., Oei, S.L., Hamm, J., Engelke, U., and Erdmann, V.A. 1985b. Functional domains of the Xenopus laevis 5 S gene promoter. $E M B O$ J. 4: 3751-3756.

Pieler, T., Hamm, J., and Roeder, R.G. 1987. The 5 S gene internal control region is composed of three distinct sequence elements, organized as two functional domains with variable spacing. Cell 48: 91-100.

Pluta, K., Lefebvre, O., Martin, N.C., Smagowicz, W.J., Stanford, D.R., Ellis, S.R., Hopper, A.K., Sentenac, A., and Boguta, M. 2001. Maf1p, a negative effector of RNA polymerase III in Saccharomyces cerevisiae. Mol. Cell. Biol. 21: 5031-5040.

Rameau, G., Puglia, K., Crowe, A., Sethy, I., and Willis, I.M. 1994. A mutation in the second largest subunit of TFIIIC increases a rate-limiting step in transcription by RNA polymerase III. Mol. Cell. Biol. 14: 822-830.

Roberts, S., Colbert, T., and Hahn, S. 1995. TFIIIC determines RNA polymerase III specificity at the TATA-containing yeast U6 promoter. Genes \& Dev. 9: 832-842.

Roberts, S., Miller, S.J., Lane, W.S., Lee, S., and Hahn, S. 1996. 
Cloning and functional characterization of the gene encoding the TFIIIB90 subunit of RNA polymerase III transcription factor TFIIIB. J. Biol. Chem. 271: 14903-14909.

Rowland, O. and Segall, J. 1998. A hydrophobic segment within the 81-amino-acid domain of TFIIIA from Saccharomyces cerevisiae is essential for its transcription factor activity. Mol. Cell. Biol. 18: 420-432.

Rüth, J., Conesa, C., Dieci, G., Lefebvre, O., Dusterhoft, A., Ottonello, S., and Sentenac, A. 1996. A suppressor of mutations in the class III transcription system encodes a component of yeast TFIIIB. EMBO I. 15: 1941-1949.

Sadhale, P.P. and Woychik, N.A. 1994. C25, an essential RNA polymerase III subunit related to the RNA polymerase II subunit RPB7. Mol. Cell. Biol. 14: 6164-6170.

Sadowski, C.L., Henry, R.W., Lobo, S.M., and Hernandez, N. 1993. Targeting TBP to a non-TATA box cis-regulatory element: A TBP-containing complex activates transcription from snRNA promoters through the PSE. Genes \& Dev. 7: 1535-1548.

Sadowski, C.L., Henry, R.W., Kobayashi, R., and Hernandez, N. 1996. The SNAP45 subunit of the small nuclear RNA (snRNA) activating protein complex is required for RNA polymerase II and III snRNA gene transcription and interacts with the TATA box binding protein. Proc. Natl. Acad. Sci. 93: 4289-4293.

Sakonju, S., Bogenhagen, D.F., and Brown, D.D. 1980. A control region in the center of the 5S RNA gene directs specific initiation of transcription: I. The $5^{\prime}$ border of the region. Cell 19: $13-25$.

Sakonju, S., Brown, D.D., Engelke, D., Ng, S.Y., Shastry, B.S., and Roeder, R.G. 1981. The binding of a transcription factor to deletion mutants of a $5 \mathrm{~S}$ ribosomal RNA gene. Cell 23: 665-669.

Santoro, C., Mermod, N., Andrews, P.C., and Tjian, R. 1988. A family of human CCAAT-box-binding proteins active in transcription and DNA replication: Cloning and expression of multiple cDNAs. Nature 334: 218-224.

Scheufler, C., Brinker, A., Bourenkov, G., Pegoraro, S., Moroder, L., Bartunik, H., Hartl, F.U., and Moarefi, I. 2000. Structure of TPR domain-peptide complexes: Critical elements in the assembly of the Hsp70-Hsp90 multichaperone machine. Cell 101: 199-210.

Schramm, L., Pendergrast, P.S., Sun, Y., and Hernandez, N. 2000. Different human TFIIIB activities direct RNA polymerase III transcription from TATA-containing and TATAless promoters. Genes \& Dev. 14: 2650-2663.

Schultz, M.C., Reeder, R.H., and Hahn, S. 1992. Variants of the TATA-binding protein can distinguish subsets of RNA polymerase I, II, and III promoters. Cell 69: 697-702.

Schultz, P., Marzouki, N., Marck, C., Ruet, A., Oudet, P., and Sentenac, A. 1989. The two DNA-binding domains of yeast transcription factor $\tau$ as observed by scanning transmission electron microscopy. EMBO J. 8: 3815-3824.

Schuster, C., Krol, A., and Carbon, P. 1998. Two distinct domains in Staf to selectively activate small nuclear RNA-type and mRNA promoters. Mol. Cell. Biol. 18: 2650-2658.

Segall, J., Matsui, T., and Roeder, R.G. 1980. Multiple factors are required for the accurate transcription of purified genes by RNA polymerase III. J. Biol. Chem. 255: 11986-11991.

Sepehri, S. and Hernandez, N. 1997. The largest subunit of human RNA polymerase III is closely related to the largest subunit of yeast and trypanosome RNA polymerase III. Genome Res. 7: 1006-1019.

Sepehri Chong, S., Hu, P., and Hernandez, N. 2001. Reconstitution of transcription from the human U6 small nuclear RNA promoter with eight recombinant polypeptides and a partially purified RNA polymerase III complex. J. Biol. Chem. 276: 20727-20734.

Setzer, D.R. and Brown, D.D. 1985. Formation and stability of the 5S RNA transcription complex. I. Biol. Chem. 260: 2483-2492.

Shah, S.M., Kumar, A., Geiduschek, E.P., and Kassavetis, G.A. 1999. Alignment of the $\mathrm{B}^{\prime \prime}$ subunit of RNA polymerase III transcription factor IIIB in its promoter complex. I. Biol. Chem. 274: 28736-28744.

Sharp, S., DeFranco, D., Dingermann, T., Farrell, P., and Soll, D. 1981. Internal control regions for transcription of eukaryotic tRNA genes. Proc. Natl. Acad. Sci. 78: 6657-6661.

Shen, Y., Igo, M., Yalamanchili, P., Berk, A.J., and Dasgupta, A. 1996. DNA binding domain and subunit interactions of transcription factor IIIC revealed by dissection with poliovirus 3C protease. Mol. Cell. Biol. 16: 4163-4171.

Shen, Y., Kassavetis, G.A., Bryant, G.O., and Berk, A.J. 1998. Polymerase (Pol) III TATA box-binding protein (TBP)-associated factor Brf binds to a surface on TBP also required for activated Pol II transcription. Mol. Cell. Biol. 18: 1692-1700.

Simmen, K.A., Bernues, J., Parry, H.D., Stunnenberg, H.G., Berkenstam, A., Cavallini, B., Egly, J.-M., and Mattaj, I.W. 1991. TFIID is required for in vitro transcription of the human U6 gene by RNA polymerase III. EMBO J. 10: 18531862.

Sinn, E., Wang, Z., Kovelman, R., and Roeder, R.G. 1995. Cloning and characterization of a TFIIIC2 subunit (TFIIICb) whose presence correlates with activation of RNA polymerase III-mediated transcription by adenovirus E1A expression and serum factors. Genes \& Dev. 9: 675-685.

Stefano, J.E. 1984. Purified lupus antigen La recognizes an oligouridylate stretch common to the $3^{\prime}$ termini of RNA polymerase III transcripts. Cell 36: 145-154.

Strubin, M. and Struhl, K. 1992. Yeast and human TFIID with altered DNA-binding specificity for TATA elements. Cell 68: $721-730$.

Stunkel, W., Kober, I., and Seifart, K.H. 1997. A nucleosome positioned in the distal promoter region activates transcription of the human U6 gene. Mol. Cell. Biol. 17: 4397-4405.

Swanson, R.N., Conesa, C., Lefebvre, O., Carles, C., Ruet, A., Quemeneur, E., Gagnon, J., and Sentenac, A. 1991. Isolation of TFC1, a gene encoding one of the two DNA-binding subunits of yeast transcription factor $\tau$ (TFIIIC). Proc. Nat1. Acad. Sci. 88: 4887-4891.

Taggart, A.K.P., Fisher, T.S., and Pugh, B.F. 1992. The TATAbinding protein and associated factors are components of Pol III transcription factor TFIIIB. Cell 71: 1015-1028.

Takada, S., Lis, J.T., Zhou, S., and Tjian, R. 2000. A TRF1:BRF complex directs Drosophila RNA polymerase III transcription. Cell 101: 459-469.

Tanaka, M., Lai, J.-S., and Herr, W. 1992. Promoter-selective activation domains in Oct-1 and Oct-2 direct differential activation of an snRNA and mRNA promoter. Cell 68: 755767.

Teichmann, M. and Seifart, K.H. 1995. Physical separation of two different forms of human TFIIIB active in the transcription of the U6 or the VAI gene in vitro. EMBO J. 14: 59745983.

Teichmann, M., Wang, Z., and Roeder, R.G. 2000. A stable complex of a novel transcription factor IIB-related factor, human TFIIIB50, and associated proteins mediate selective transcription by RNA polymerase III of genes with upstream promoter elements. Proc. Natl. Acad. Sci. 97: 14200-14205.

Thuillier, V., Stettler, S., Sentenac, A., Thuriaux, P., and Werner, M. 1995. A mutation in the C31 subunit of Saccharomyces cerevisiae RNA polymerase III affects transcription 
initiation. EMBO J. 14: 351-359.

Tirode, F., Busso, D., Coin, F., and Egly, J.M. 1999. Reconstitution of the transcription factor TFIIH: Assignment of functions for the three enzymatic subunits, XPB, XPD, and cdk7. Mol. Cell 3: 87-95.

Todone, F., Brick, P., Werner, F., Weinzierl, R.O., and Onesti, S. 2001. Structure of an archaeal homolog of the eukaryotic RNA polymerase II RPB4/RPB7 complex. Mol. Cell 8: 11371143.

Topper, J.N. and Clayton, D.A. 1990. Characterization of human MRP/Th RNA and its nuclear gene: Full length MRP/ Th RNA is an active endoribonuclease when assembled as an RNP. Nucleic Acids Res. 18: 793-799.

Waldschmidt, R., Wanandi, I., and Seifart, K.H. 1991. Identification of transcription factors required for the expression of mammalian U6 genes in vitro. EMBO J. 10: 2595-2603.

Wang, Y. and Stumph, W.E. 1995. RNA polymerase II/III transcription specificity determined by TATA box orientation. Proc. Natl. Acad. Sci. 92: 8606-8610.

Wang, Z. and Roeder, R.G. 1995. Structure and function of a human transcription factor TFIIIB subunit that is evolutionarily conserved and contains both TFIIB-and high-mobilitygroup protein 2-related domains. Proc. Natl. Acad. Sci. 92: 7026-7030.

- 1996. TFIIIC1 acts through a downstream region to stabilize TFIIIC2 binding to RNA polymerase III promoters. Mol. Cell. Biol. 16: 6841-6850.

- 1997. Three human RNA polymerase III-specific subunits form a subcomplex with a selective function in specific transcription initiation. Genes \& Dev. 11: 1315-1326.

- 1998. DNA topoisomerase I and PC4 can interact with human TFIIIC to promote both accurate termination and transcription reinitiation by RNA polymerase III. Mol. Cell 1: 749-757.

Wang, Z., Luo, T., and Roeder, R.G. 1997. Identification of an autonomously initiating RNA polymerase III holoenzyme containing a novel factor that is selectively inactivated during protein synthesis inhibition. Genes \& Dev. 11: 23712382 .

Wang, Z., Bai, L., Hsieh, Y.J., and Roeder, R.G. 2000. Nuclear factor 1 (NF1) affects accurate termination and multipleround transcription by human RNA polymerase III. EMBO $J$. 19: 6823-6832.

Werner, M., Hermann-Le Denmat, S., Treich, I., Sentenac, A., and Thuriaux, P. 1992. Effect of mutations in a zinc-binding domain of yeast RNA polymerase C (III) on enzyme function and subunit association. Mol. Cell. Biol. 12: 1087-1095.

Werner, M., Chaussivert, N., Willis, I.M., and Sentenac, A. 1993. Interaction between a complex of RNA polymerase III subunits and the $70-\mathrm{kDa}$ component of transcription factor IIIB. J. Biol. Chem. 268: 20721-20724.

White, R.J. and Jackson, S.P. 1992. Mechanism of TATA-binding protein recruitment to a TATA-less class III promoter. Cell 71: 1041-1053.

White, R.J., Jackson, S.P., and Rigby, P.W.J. 1992. A role for the TATA-box-binding protein component of the transcription factor IID complex as a general RNA polymerase III transcription factor. Proc. Natl. Acad. Sci. 89: 1949-1953.

Whitehall, S., Kassavetis, G.A., and Geiduschek, E.P. 1995. The symmetry of the yeast U6 RNA gene's TATA box, and the orientation of the TATA-binding protein in yeast TFIIIB. Genes \& Dev. 9: 2974-2985.

Willis, I.M. 2002. A universal nomenclature for subunits of the RNA polymerase III transcription initiation factor TFIIIB. Genes \& Dev. 16: 1337-1338.

Willis, I., Schmidt, P., and Soll, D. 1989. A selection for mutants of the RNA polymerase III transcription apparatus: PCF1 stimulates transcription of tRNA and 5S RNA genes. EMBO I. 8: 4281-4288.

Wolffe, A.P., Jordan, E., and Brown, D.D. 1986. A bacteriophage RNA polymerase transcribes through a Xenopus 5S RNA gene transcription complex without disrupting it. Cell 44: 381-389.

Wong, M.W., Henry, R.W., Ma, B., Kobayashi, R., Klages, N., Matthias, P., Strubin, M., and Hernandez, N. 1998. The large subunit of basal transcription factor $\mathrm{SNAP}_{\mathrm{c}}$ is a Myb domain protein that interacts with Oct-1. Mol. Cell. Biol. 18: 368377.

Woychik, N.A. and Hampsey, M. 2002. The RNA polymerase II machinery: Structure illuminates function. Cell 108: 453463.

Woychik, N.A. and Young, R.A. 1989. RNA polymerase II subunit RPB4 is essential for high- and low-temperature yeast cell growth. Mol. Cell. Biol. 9: 2854-2859.

Yamashita, S., Hisatake, K., Kokubo, T., Doi, K., Roeder, R.G., Horikoshi, M., and Nakatani, Y. 1993. Transcription factor TFIIB sites important for interaction with promoter-bound TFIID. Science 261: 463-466.

Yang, Z., Zhu, Q., Luo, K., and Zhou, Q. 2001. The 7SK small nuclear RNA inhibits the CDK9/cyclin T1 kinase to control transcription. Nature 414: 317-322.

Yoon, J.-B. and Roeder, R.G. 1996. Cloning of two proximal sequence element-binding transcription factor subunits $(\gamma$ and $\delta$ ) that are required for transcription of small nuclear RNA genes by RNA polymerases II and III and interact with the TATA-binding protein. Mol. Cell. Biol. 16: 1-9.

Yoon, J.-B., Murphy, S., Bai, L., Wang, Z., and Roeder, R.G. 1995. Proximal sequence element-binding transcription factor (PTF) is a multisubunit complex required for transcription of both RNA polymerase II- and RNA polymerase III-dependent small nuclear RNA genes. Mol. Cell. Biol. 15: 20192027.

Yoshinaga, S.K., Boulanger, P.A., and Berk, A.J. 1987. Resolution of human transcription factor TFIIIC into two functional components. Proc. Natl. Acad. Sci. 84: 3585-3589.

Yoshinaga, S.K., L'Etoile, N.D., and Berk, A.J. 1989. Purification and characterization of transcription factor IIIC2. J. Biol. Chem. 264: 10726-10731.

Yukawa, Y., Sugita, M., Choisne, N., Small, I., and Sugiura, M. 2000. The TATA motif, the CAA motif and the poly(T) transcription termination motif are all important for transcription re-initiation on plant tRNA genes. Plant J. 22: 439-447.

Zhao, X., Pendergrast, P.S., and Hernandez, N. 2001. A positioned nucleosome on the human U6 promoter allows recruitment of $\mathrm{SNAP}_{\mathrm{c}}$ by the Oct-1 POU domain. Mol. Cell 7: 539-549.

Zhu, W., Zeng, Q., Colangelo, C.M., Lewis, M., Summers, M.F., and Scott, R.A. 1996. The N-terminal domain of TFIIB from Pyrococcus furiosus forms a zinc ribbon. Nat. Struct. Biol. 3: 122-124. 


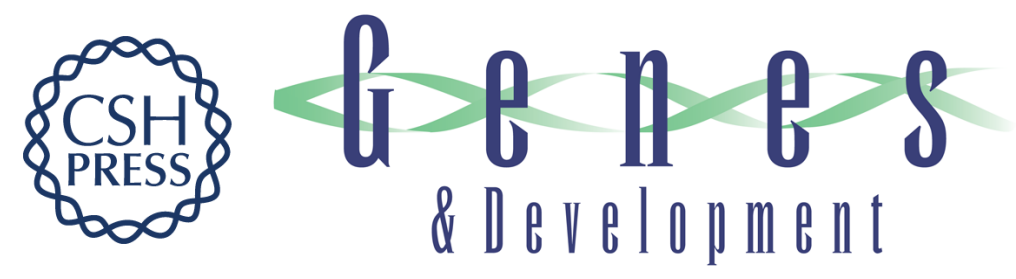

\section{Recruitment of RNA polymerase III to its target promoters}

Laura Schramm and Nouria Hernandez

Genes Dev. 2002, 16:

Access the most recent version at doi:10.1101/gad.1018902

References This article cites 224 articles, 128 of which can be accessed free at: http://genesdev.cshlp.org/content/16/20/2593.full.html\#ref-list-1

License

Email Alerting Receive free email alerts when new articles cite this article - sign up in the box at the top Service right corner of the article or click here.

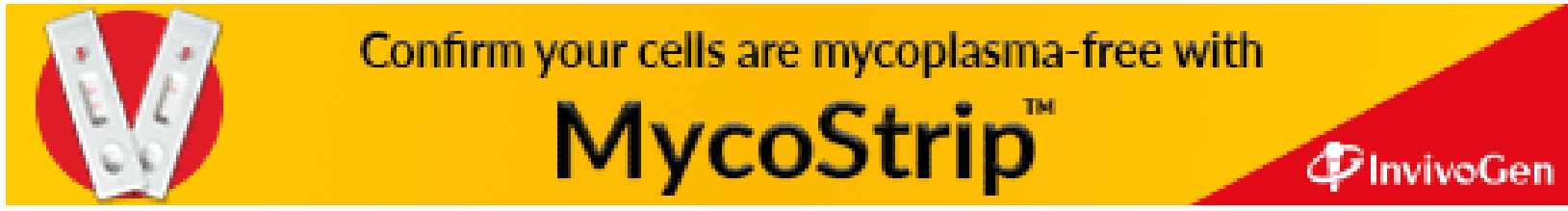

